\title{
Validation of Two-Phase Flow Model for Leachate Recirculation in Bioreactor Landfills
}

\author{
Krishna R. Reddy, Rajiv K. Giri, and Hanumanth S. Kulkarni \\ Department of Civil \& Materials Engineering, University of Illinois at Chicago, 842 West Taylor Street, Chicago, IL 60607, USA \\ Correspondence should be addressed to Krishna R. Reddy; kreddy@uic.edu
}

Received 24 January 2014; Accepted 2 July 2014; Published 20 August 2014

Academic Editor: Gopal Achari

Copyright (C) 2014 Krishna R. Reddy et al. This is an open access article distributed under the Creative Commons Attribution License, which permits unrestricted use, distribution, and reproduction in any medium, provided the original work is properly cited.

\begin{abstract}
A numerical two-phase flow model is presented to determine the moisture distribution and pore water and gas pressures within unsaturated municipal solid waste (MSW) in bioreactor landfills during leachate recirculation. The numerical model used is the Fast Lagrangian Analysis of Continua (FLAC), which is based on finite difference approach. The model governing equations and mathematical formulations is briefly explained. Validation of the model is examined by simulating the published laboratory and field studies and published modeling studies. Overall, the two-phase flow model is found to produce results comparable with those of the published studies. This assures that the model can be used for the prediction of moisture distribution and for the rational design of leachate recirculation systems in bioreactor landfills.
\end{abstract}

\section{Introduction}

Bioreactor landfills, emerging as a preferred option for the municipal solid waste (MSW) management, essentially involve the recirculation of leachate to increase the moisture content of the MSW and, thus, its biodegradation. For bioreactor landfills to be effective, the uniform and adequate distribution of moisture throughout the MSW is of paramount importance.

The proper design of a leachate recirculation system is an important task to ensure the uniform distribution of moisture with the desired saturation levels, which range from $60 \%$ to $80 \%$ [1]. This range can be achieved if the design of the leachate recirculation systems takes various elements into consideration, including (a) hydraulic properties of MSW (including saturated and unsaturated hydraulic conductivity), (b) selection of the proper type of leachate recirculation system, (c) optimization of the geometric formation and configuration of the selected leachate recirculation system, and (d) spatial variation of the MSW hydraulic properties.

The published literature generally considers the leachate routing in a bioreactor landfill by assuming (a) saturated
MSW, (b) single phase flow, (c) homogeneous and anisotropic MSW, or (d) improper hydraulic parameters of MSW. Therefore, the accuracy of the literature is often called into question. The current leachate recirculation systems design and operational suggestions are based on limited laboratory studies and field observations and their application has resulted in wide variations in overall bioreactor performance. In addition, the field studies that use geophysical methods (e.g., ERT imaging) have provided useful but limited information on the leachate movement in the landfill. It is of utmost importance to have a rational method to design effective leachate recirculation systems; this can be accomplished by simulating near field situations using advanced mathematical modeling tools.

In this study, the Fast Lagrangian Analysis of Continua (FLAC) model is employed to model the leachate distribution in bioreactor landfill [2], and this paper examines the validation of this model. Since the MSW is an unsaturated porous media, the flow of leachate as the wetting fluid and landfill gas as the nonwetting fluid is considered. Therefore, two-phase flow modeling is performed in which the two immiscible fluids considered are water and air. The governing equations concerning the numerical model are described. To assure the 
accuracy of its predictions, the model is validated based on several previously published laboratory, field, and modeling studies.

\section{Modeling Methodology}

2.1. Governing Equations. Unsaturated MSW pores contain two immiscible fluids, namely, landfill leachate (i.e., wetting fluid) and gas (i.e., nonwetting fluid), simultaneously, and their flow is governed by leachate saturation, capillary pressure (pressure difference between pore gas and pore water), and relative hydraulic conductivities. The numerical two-phase flow model enables and simulates modeling the flow of these two immiscible fluids. The flow of liquid (with superscript " $L$ ") and gas (with superscript " $g$ ") is described by Darcy's law:

$$
\begin{gathered}
q_{i}^{L}=-k_{i j}^{L} \kappa_{r}^{L} \frac{\partial}{\partial x_{j}}\left(P_{L}-\rho_{L} g_{k} x_{k}\right) \\
q_{i}^{g}=-k_{i j}^{L} \frac{\mu_{w}}{\mu_{g}} \kappa_{r}^{g} \frac{\partial}{\partial x_{j}}\left(P_{g}-\rho_{g} g_{k} x_{k}\right),
\end{gathered}
$$

where $k_{i j}=$ saturated mobility coefficient (tensor) defined as the ratio of intrinsic permeability to dynamic viscosity; $i=$ number of zones in horizontal $(x)$ direction; $j=$ number of zones in vertical $(y)$ direction; $\kappa_{r}=$ relative permeability for the fluid (function of saturation); $\mu=$ dynamic viscosity; $P=$ pore pressure; $\rho=$ fluid density, and $g=$ acceleration due to gravity.

The relative permeabilities are related to saturation $\left(S_{L}\right)$ and are expressed by van Genuchten functions:

$$
\begin{aligned}
& \kappa_{r}^{L}=S_{e}^{b}\left[1-\left(1-S_{e}^{1 / a}\right)^{a}\right]^{2}, \\
& \kappa_{r}^{g}=\left(1-S_{e}\right)^{c}\left[1-S_{e}^{1 / a}\right]^{2 a}, \\
& S_{e}=\frac{S_{L}-S_{r}^{L}}{1-S_{r}^{L}}
\end{aligned}
$$

where $a, b$, and $c$ are constant parameters for van Genuchten function, $S_{e}=$ effective saturation, and $S_{r}=$ residual wetting fluid saturation.

Capillary pressure is related to the pressure difference between the liquid and gas as

$$
P_{g}-P_{L}=P_{c}\left(S_{L}\right)
$$

where $P_{g}=$ pressure created by nonwetting fluid; $P_{L}=$ pressure created by liquid; $P_{c}\left(S_{L}\right)=$ capillary pressure, which is a function of degree of saturation $\left(S_{L}\right)$. The sum of the saturation of liquid $\left(S_{L}\right)$ and gas $\left(S_{g}\right)$ should be

$$
S_{L}+S_{g}=1
$$

Fluid balance laws for the slightly compressible fluids provide the variation of fluid content (variation of fluid volume per unit volume of porous material) with respect to the volumetric fluid source intensity. They are given by

$$
\begin{aligned}
& \frac{\partial \xi_{L}}{\partial t}=-\frac{\partial q_{i}^{L}}{\partial x_{i}}+q_{v}^{L}, \\
& \frac{\partial \xi_{G}}{\partial t}=-\frac{\partial q_{i}^{G}}{\partial x_{i}}+q_{v}^{G},
\end{aligned}
$$

where $\xi=$ variation of fluid volume per unit volume of porous material, and $q_{v}=$ volumetric fluid source intensity.

Constitutive laws for fluids are solved for the pressures in liquid and gas and saturation in liquid and gas fluids:

$$
\begin{gathered}
S_{L} \frac{\partial P_{L}}{\partial t}=\frac{K_{L}}{n}\left[\frac{\partial \xi_{L}}{\partial t}-n \frac{\partial S_{L}}{\partial t}-S_{L} \frac{\partial \epsilon}{\partial t}\right] \\
S_{G} \frac{\partial P_{G}}{\partial t}=\frac{K_{G}}{n}\left[\frac{\partial \xi_{G}}{\partial t}-n \frac{\partial S_{G}}{\partial t}-S_{G} \frac{\partial \epsilon}{\partial t}\right] .
\end{gathered}
$$

By combining these equations with fluid balance laws,

$$
\begin{gathered}
n\left[\frac{S_{L}}{K_{L}} \frac{\partial P_{L}}{\partial t}+\frac{\partial S_{L}}{\partial t}\right]=-\left[\frac{\partial q_{i}^{L}}{\partial x_{i}}+S_{L} \frac{\partial \epsilon}{\partial t}\right], \\
n\left[\frac{S_{G}}{K_{G}} \frac{\partial P_{G}}{\partial t}+\frac{\partial S_{G}}{\partial t}\right]=-\left[\frac{\partial q_{i}^{G}}{\partial x_{i}}+S_{G} \frac{\partial \epsilon}{\partial t}\right] .
\end{gathered}
$$

This gives a nonlinear system of four equations in terms of four unknowns $P_{L}, P_{G}, S_{L}$, and $S_{G}$. In the fluid flow only calculation, term $[\partial \epsilon / \partial t]$ is ignored.

The governing equations of the two-phase model consist of the linear momentum balance and the fluid balance laws (based on mass balance), and these are represented as

$$
\begin{aligned}
& \rho=\rho_{d}+n\left(S_{L} \rho_{L}+S_{G} \rho_{G}\right), \\
& n\left[\frac{S_{L}}{K_{L}} \frac{\partial P_{L}}{\partial t}+\frac{\partial S_{L}}{\partial t}\right]=-\left[\frac{\partial q_{i}^{L}}{\partial x_{i}}\right], \\
& n\left[\frac{S_{G}}{K_{G}} \frac{\partial P_{G}}{\partial t}+\frac{\partial S_{G}}{\partial t}\right]=-\left[\frac{\partial q_{i}^{G}}{\partial x_{i}}\right],
\end{aligned}
$$

where $n$ is the porosity, $S_{L}$ is the wetting leachate (liquid) saturation, $S_{G}$ is the nonwetting gas saturation, $P_{L}$ is the wetting pore liquid pressure, $P_{G}$ is the nonwetting pore gas pressure, $\rho_{L}$ and $\rho_{G}$ are the fluid densities, $\rho_{d}$ is the matrix dry density, $K_{L}$ and $K_{G}$ are the liquid and gas bulk modulus, respectively, $q_{i}^{L}$ and $q_{i}^{G}$ are the flow rate of wetting liquid and nonwetting gas given by Darcy's law.

The governing equations of the two-phase flow model (8) are solved in FLAC that uses the finite difference method. FLAC program was selected as it enables the realistic generation and distribution of moisture and pore pressures through porous MSW. The detailed mathematical formulation including governing equations and numerical formulations related to the two-phase flow model are presented elsewhere $[2,3]$. 


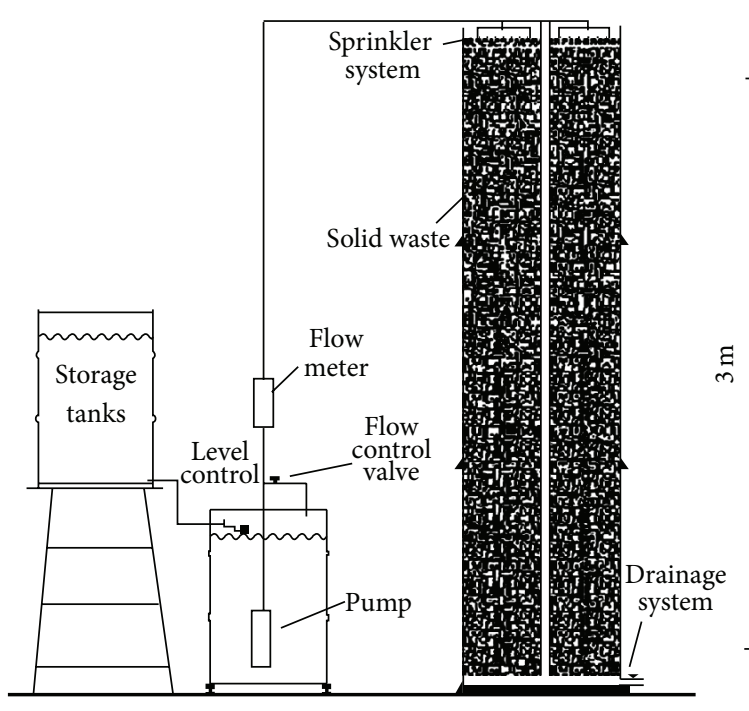

(a)

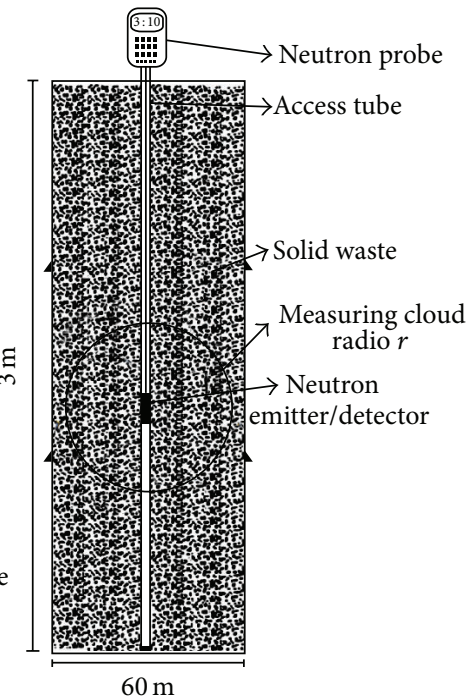

$60 \mathrm{~m}$

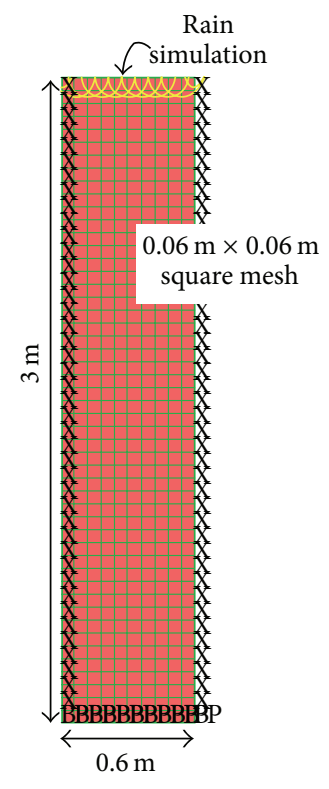

(b)

FIGURE 1: (a) Experimental column setup to measure the moisture distribution in a laboratory scale testing [4]; (b) model discretization in two-phase flow model for the model validation.

\section{Validation with Laboratory Studies}

3.1. Capelo and de Castro [4] Study. Transient flow of water in an unsaturated MSW was studied in laboratory-scale experiments by Capelo and de Castro [4], who simulated a tropical rain event based on the absolute moisture content and moisture variation in a sample of MSW collected from a sanitary landfill in Fortaleza, Ceara, Brazil. The investigators employed neutron scattering to monitor the variation of the absolute moisture content in three leaching experimental columns. Each column was $3 \mathrm{~m}$ in depth and $0.6 \mathrm{~cm}$ in its internal diameter (Figure 1(a)). Drainage was provided at the bottom of the column by a perforated PVC pipe and a $10 \mathrm{~cm}$ layer of crushed bricks. The sample was compacted with $20 \mathrm{~cm}$ layer thickness to fill the columns to a density of $550 \mathrm{~kg} / \mathrm{m}^{3}$. They presented the variation of volumetric moisture content with depth in all the three columns during a simulation of rain conditions and reported on the moisture distribution during the free drain condition for columns one and two. In column one, the flow density for rain simulation was $9.50 \mathrm{~cm} / \mathrm{h}$ and the observations were registered for a total of $390 \mathrm{~min}$ at $30 \mathrm{~min}$ intervals with the data reported at every $30 \mathrm{~cm}$ change in depth. For columns two and three, the flow density for rain simulation was $14.25 \mathrm{~cm} / \mathrm{h}$ with observations registered for $160 \mathrm{~min}$ at $30 \mathrm{~min}$ intervals, again at every $30 \mathrm{~cm}$ change in depth. The results [4] showed that the water content started building up at a depth ranging between 180 and $210 \mathrm{~cm}$ instead of accumulating from the bottom (Figure 1(a)).

To simulate the moisture distribution in the experimental cell described by [4], a model was selected that is $3 \mathrm{~m}$ high and $0.6 \mathrm{~m}$ in diameter. Based on the grid size analysis, this model is discretized into small square grids that are $0.06 \mathrm{~m}$ in size. All the boundaries are assumed to be impermeable. During the original rain simulation, the bottom valve in the experimental cylinder was closed to allow the accumulation of leachate at the bottom. Therefore, to provide an accurate simulation, the bottom most grid points are not fixed to zero pore pressure. Later, when the experiment contains the free drain condition on columns one and two, the bottom most grid points are assigned to have zero pore water pressures for computation of the leachate outflow rate. Since the FLAC model simulations include the flow only calculations, the mechanical computations are not performed. The deformation in the lateral directions is fixed to zero, and the base of the cell is fixed to zero for the lateral and vertical deformations.

The MSW in the columns is assumed to be isotropic and heterogeneous. The initial model parameters are summarized in Table 1. The initial pore water pressures of leachate and gas fluids are assumed to be zero at all grid points. The unsaturated hydraulic parameters of MSW suggested by Stoltz et al. [5] are used. These properties are assumed to be valid for the MSW used by Capelo and de Castro [4]. The initial porosity of the MSW varied from $40 \%$ to $80 \%$ and the final value of $77 \%$ is selected based on the calibration.

Mechanical properties of the MSW, such as the elastic (bulk modulus and shear modulus) and plastic parameters (cohesion, tension, friction angle, and dilation angle) values, are selected so as to result in zero deformation after solving for the initial equilibrium since the subsequent analysis is performed for the flow only scenario. The respective values are summarized in Table 2 . The plastic properties for 
TABLE 1: Initial conditions and materials properties used for model validation for the published laboratory studies.

\begin{tabular}{|c|c|c|c|}
\hline Parameter & Value & Remarks & Source \\
\hline Residual moisture content $\left(\theta_{r}\right)(\%)$ & 20 & \multirow{5}{*}{$\begin{array}{l}\text { Laboratory experiments conducted on fresh } \\
\text { MSW collected from French Bioreactor } \\
\text { Landfill }\end{array}$} & \multirow{5}{*}{ Stoltz et al. [5] } \\
\hline van Genuchten parameter $(\alpha)(/ \mathrm{kPa})$ & 2.9 & & \\
\hline van Genuchten parameter $(a)$ & 0.318 & & \\
\hline van Genuchten parameter $(b)$ & 0.50 & & \\
\hline van Genuchten parameter $(c)$ & 0.50 & & \\
\hline Porosity $(n)(\%)$ & 68 & & Hudson et al. [16] \\
\hline Saturated hydraulic conductivity $\left(k_{\text {sat }}\right)(\mathrm{cm} / \mathrm{s})$ & $4.8 \times 10^{-5}$ & $\begin{array}{l}\text { Laboratory experiments conducted on fresh } \\
\text { MSW collected from French Bioreactor } \\
\text { Landfill }\end{array}$ & Staub et al. [7] \\
\hline Bulk modulus of MSW $(\mathrm{Pa})$ & $3.5 \times 10^{5}$ & \multirow{2}{*}{ Calibrated } & \multirow{2}{*}{-} \\
\hline Shear modulus of MSW $(\mathrm{Pa})$ & $0.8 \times 10^{5}$ & & \\
\hline Unit weight of MSW $\left(\mathrm{kg} / \mathrm{m}^{3}\right)$ & 1050 & $\begin{array}{l}\text { Laboratory experiments conducted on MSW } \\
\text { collected from Cleanway Waste Disposal, } \\
\text { Essex, UK }\end{array}$ & Hudson et al. [16] \\
\hline
\end{tabular}

TABLE 2: Mechanical properties used for model validations for the published laboratory studies.

\begin{tabular}{llll}
\hline Parameter & Value & Remarks & Source \\
\hline & & Elastic properties & - \\
Bulk modulus of MSW $(\mathrm{Pa})$ & $1.5 \times 10^{5}$ & Varied between 1.0e5 to 4.5e5 & - \\
Shear modulus of MSW $(\mathrm{Pa})$ & $1.0 \times 10^{5}$ & Varied between 1.0e5 to 2.0e5 & Oboratory experiments conducted on fresh \\
Unit weight of MSW $\left(\mathrm{kg} / \mathrm{m}^{3}\right)$ & 750 & MSW collected from French Bioreactor Landfill & Oliver and Gourc [17] \\
\hline
\end{tabular}

the Mohr-Coulomb model are selected from the published literature [6]. The density of the MSW assumed is $550 \mathrm{~kg} / \mathrm{m}^{3}$ as given by Capelo and de Castro [4].

The FLAC modeling scenarios include a rain simulation conducted by injecting the leachate at the rate of $9.5 \mathrm{~cm} / \mathrm{hr}$ in column one for up to $390 \mathrm{~min}$ at $30 \mathrm{~min}$ intervals and injecting the leachate with $14.25 \mathrm{~cm} / \mathrm{hr}$ rain intensity in columns two and three for up to $160 \mathrm{~min}$ with the time intervals of $0,30,60,100,130$, and $160 \mathrm{~min}$. The rain intensity is applied in the form of the discharge at the top of the model. Once the rain simulation is completed in column one, the effect of gravity drainage is evaluated by fixing the zero pore water pressure at the bottom grid points; observations are noted at different time intervals. In the case of column two, once the rain simulation is completed, the cell is saturated for $200 \mathrm{~min}$, and then the gravity drainage is allowed for 14 days with measurements taken at different time intervals. In the case of column three, only the rain simulation with the rain intensity of $14.25 \mathrm{~cm} / \mathrm{hr}$ is replicated, done at the time intervals of $0,30,60,100,130$, and $160 \mathrm{~min}$. The effect of gravity drainage in column three is not simulated. The results of the saturation profile, pore water pressure distribution, and volumetric moisture content with respect to the cell height during rain simulations in all three columns and during gravity drainage in columns one and two are analyzed and compared.

The model simulations were performed to validate the model for the study of moisture distribution and were compared to the published experimental values as given by Capelo and de Castro [4] for columns two and three. The rain simulation modeled in column two had a rain intensity of $14.25 \mathrm{~cm} / \mathrm{hr}$. The initial moisture content of the MSW, before the leachate injection, is $13.2 \%$. A minor variation in the moisture content is observed in the shallow layers of the cell when the leachate is injected in column one. As the injection continues, a general trend of accumulation of high moisture occurs in the deep layers located between $1.5 \mathrm{~m}$ and $3 \mathrm{~m}$ due to the low permeability in these layers. Figure 2 compares the model results with the experimental results by Capelo and de Castro [4]. For the analysis of the free drainage in column two, the leachate was injected until the overall saturation of the cell reached $100 \%$. During the rain simulation in column two, the moisture content was recorded using the neutron probe every $30 \mathrm{~min}$ at a point located $30 \mathrm{~cm}$ from the top of the cell. Results obtained for free drainage in column two indicated less moisture content after 14 days in the cell. The volumetric moisture content plotted in Figures 2(a) and 2(b) consists of few data points that are not in agreement with the model predictions, which may be due to the heterogeneity of the MSW.

The rain simulation in column three is modeled with an infiltration rate of $14.25 \mathrm{~cm} / \mathrm{hr}$. Model predictions include saturation contours and pore water pressure distribution in the column. The volumetric moisture content was computed based on the computed saturation profile of the column and was recorded for $160 \mathrm{~min}$ at every $30 \mathrm{~min}$ interval at every 


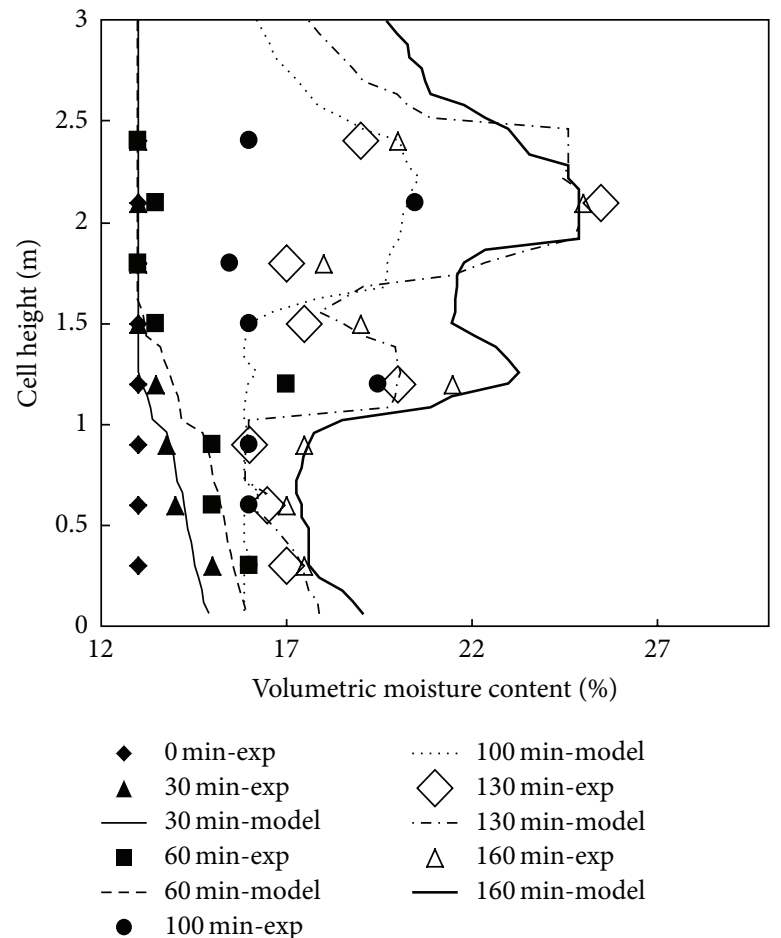

(a)

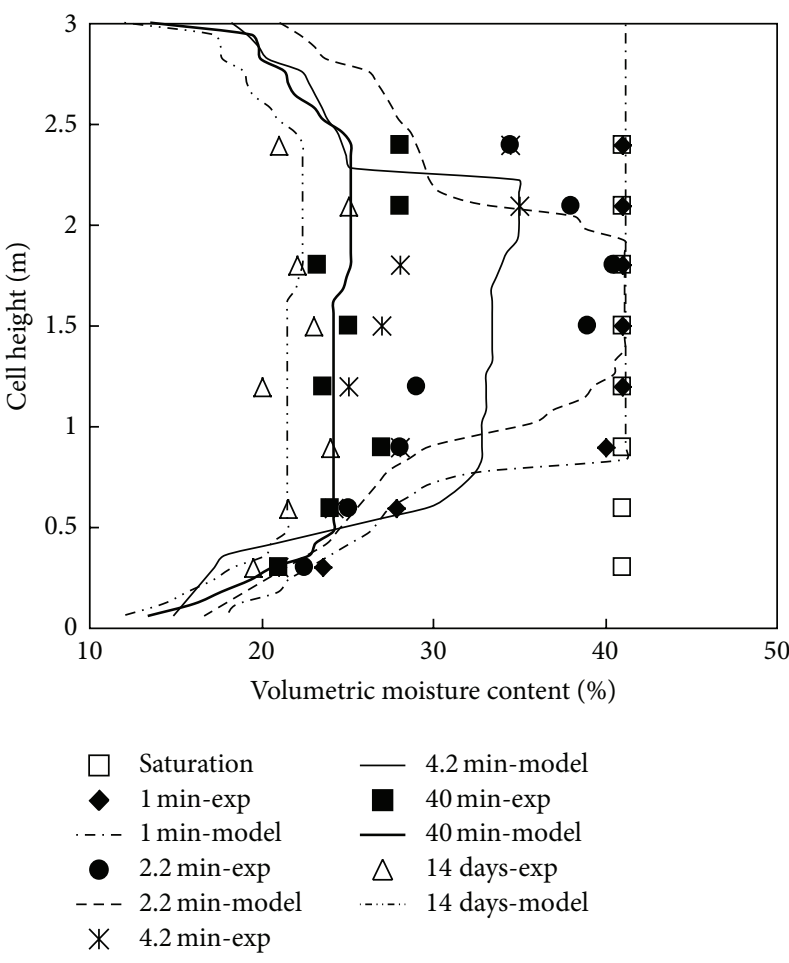

(b)

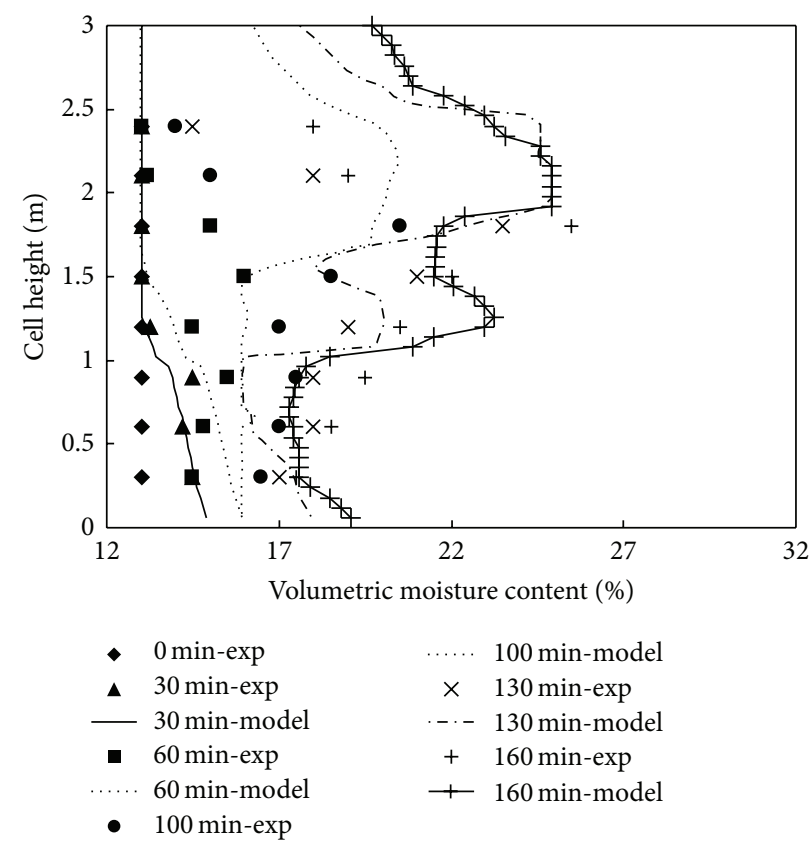

(c)

FIGURE 2: Volumetric moisture content: (a) during rain simulation in column two; (b) during free drain in column two; (c) during rain simulation in column three.

$30 \mathrm{~cm}$ depth. Given that the shallow layers possess relatively high permeability, it is clear that the injected leachate tends to migrate downward during the initial 60 min (Figure 2(c)). Furthermore, as leachate migrates to the bottom layers for the next $120 \mathrm{~min}$ and afterwards, a higher saturation level in the MSW is observed due to the decreasing saturated hydraulic conductivity with the column depth. However, the higher saturation levels are observed only between the column depths of $150 \mathrm{~cm}$ to $300 \mathrm{~cm}$, for the measurements taken at the 60 min mark and later injection times, as those depths possess relatively low permeability in the column (Figure 2(c)). Overall, the comparison of results predicted by 


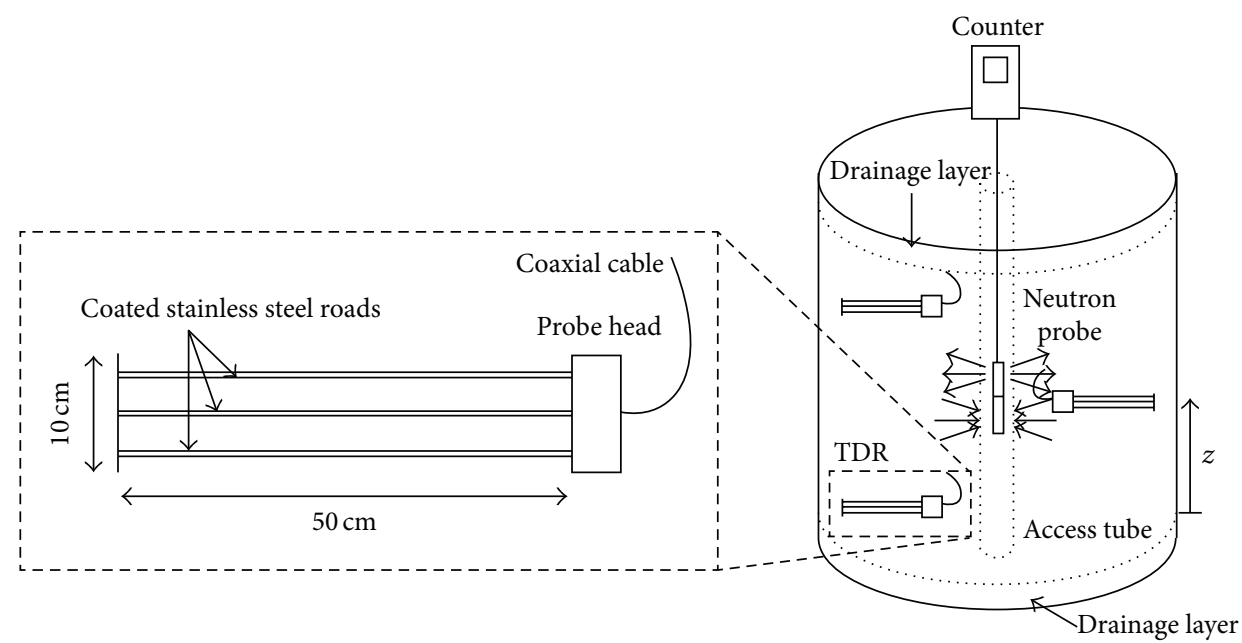

(a)

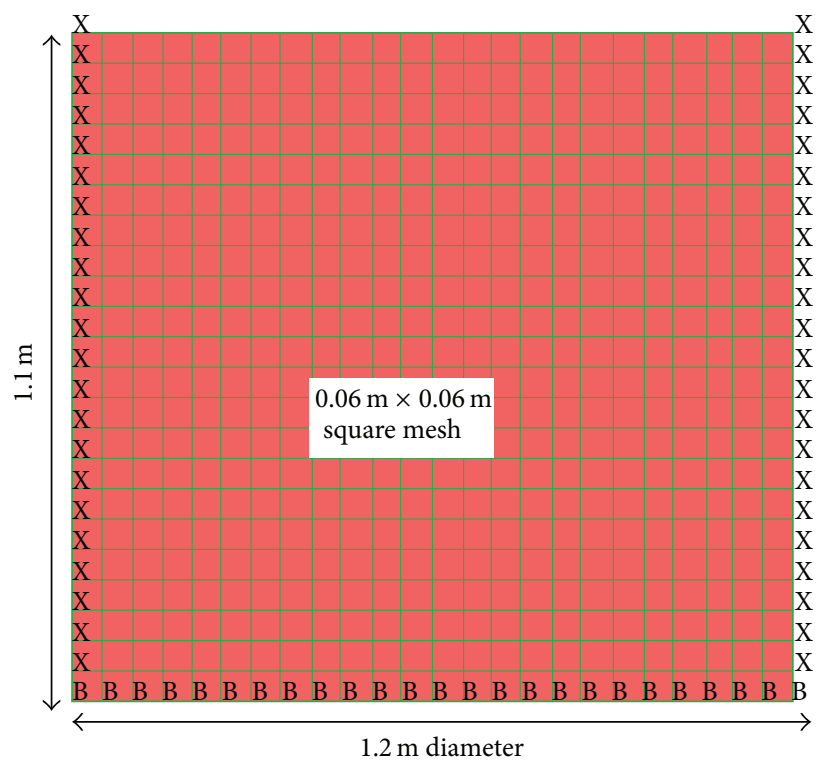

(b)

FiguRE 3: (a) Laboratory setup; (b) model discretization of laboratory setup in two-phase flow model.

Capelo and de Castro [4] show that the numerical FLAC model can be relied on to reasonably simulate moisture distribution in unsaturated MSW in the column and can be applied to model moisture distribution in bioreactor landfills.

3.2. Staub et al. [7] Study. A large-scale laboratory study on the long-term moisture distribution in MSW during leachate recirculation was reported by Staub et al. [7] (Figure 3(a)). This study collected MSW and the leachate to be recirculated from an active landfill in France. Six cells with different leachate recirculation scenarios were used; one of these cells was selected for this study. Cell B1 with MSW compacted with a dry density of $0.45 \mathrm{t} / \mathrm{m}^{3}$ and initial volumetric moisture content of $22 \%$ was saturated initially for 30 days with 328 liters of leachate injected from the bottom and then allowed gravity drainage drained for 199 days. Data from the upper $0.3 \mathrm{~m}$ and bottom $0.1 \mathrm{~m}$ was not provided by Staub et al. [7] due to measurement problems.

The experimental cell B1 was simulated in a two-phase flow model using a model domain of $1.1 \mathrm{~m}$ wide by $1.2 \mathrm{~m}$ high (Figure 3(b)). The moisture distribution during the leachate injection from the bottom of the cell is simulated for 199 days, as indicated by original investigators. Once the system attained steady state conditions, the effect of subsequent gravity drainage for four weeks on moisture distribution is investigated. The changes in saturation, pore water pressure, and leachate outflow at the bottom of the landfill during the gravity drainage are computed.

The model is validated in comparison with the experimental results presented by Staub et al. [7] (Figure 4). The volumetric moisture content measurements for days 31, 32, 


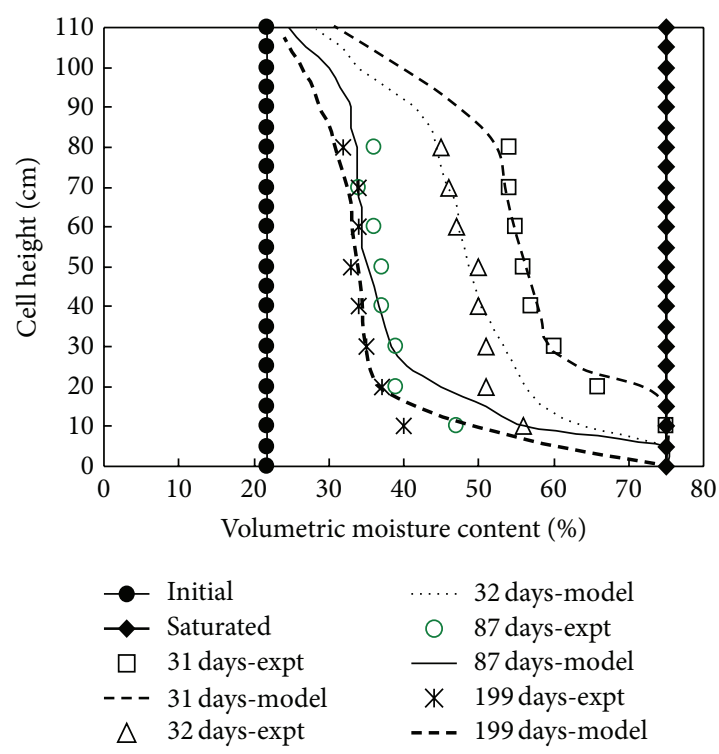

(a)

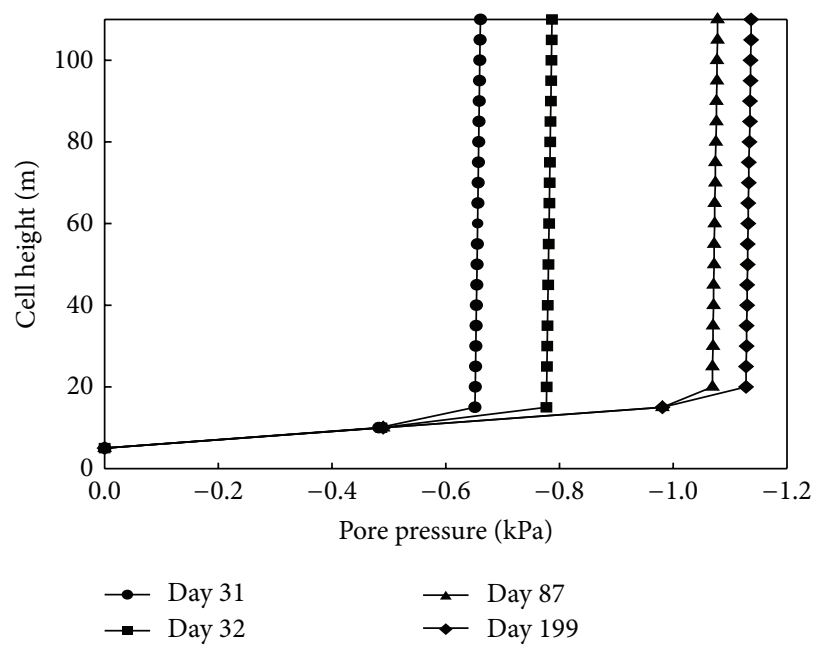

(b)

FIgURE 4: (a) Moisture content and (b) pore pressure distribution with cell height for days 31, 32, 87, and 199.

87, and 199 are in good agreement with the experimental data (Figure 4(a)). Further, the model provides the pore water pressure distribution in the cell during the drainage process (Figure 4(b)). When gravity drainage is initiated, the moisture at the bottom of the cell drains out and creates more space for the leachate amassed in the top layers to flow towards the bottom where it accumulates. Therefore, the volumetric moisture content is higher near the drainage layer. The Staub et al. [7] laboratory study did not include a few data points near the top and bottom of the cell because of errors, but the model simulation results do include data for these locations. The development of negative pore water pressure in the cell as shown in Figure 4(b) and it can be seen that the moisture content is almost the same from the cell height $0.25 \mathrm{~m}$ to the height of $0.9 \mathrm{~m}$ and the variation in the pore pressure in this region is almost negligible. Thus, the pore pressure developed remains the same from top of the cell. Further, negative pore pressure development is due to the draining of leachate which returns the MSW to previously unsaturated conditions, whereby the MSW may experience the flow of two immiscible fluids. This demonstrates the need for two-phase fluid flow analysis in unsaturated MSW.

\section{Validation with Field Studies}

4.1. Haydar and Khire [8] Study. Moisture distribution at a landfill site utilizing drainage blanket (DB) as the leachate recirculation system was evaluated by Haydar and Khire [8]. Shredded scrap tires with a maximum particle size of $100 \mathrm{~mm}$ were used as the backfill or drainage material in the DB. This material was laid on the compacted surface of MSW to create a $50 \mathrm{~cm}$ high layer. Temperature gauges and moisture sensors were installed within the DB to measure variation in temperature and moisture. Leachate was injected for twenty

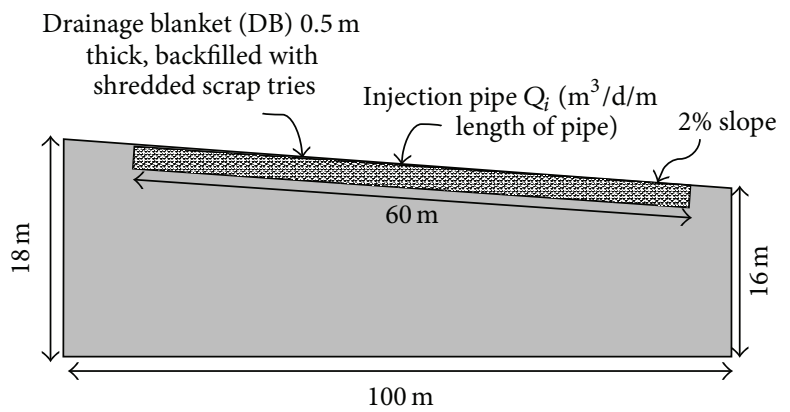

(a)

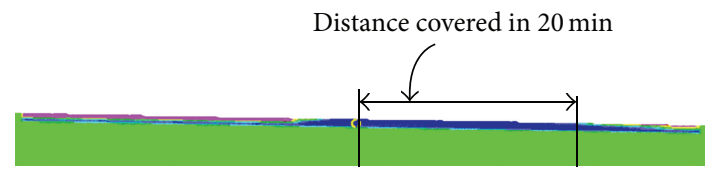

(b)

FIGURE 5: (a) Field study on drainage blanket by Khire and Haydar [8]; (b) maximum distance covered within DB during 20 minutes of leachate recirculation measured from the leachate injection pipe with respect to saturation greater than $90 \%$.

minutes and then the investigators measured the maximum distance the leachate travelled in the DB: the rate of injection was $62.4 \mathrm{~m}^{3} / \mathrm{day} / \mathrm{m}$ length of the injection pipe.

For the FLAC two-phase flow numerical model, the landfill is assumed to be $180 \mathrm{~m}$ wide, $18 \mathrm{~m}$ high at the east end, and $16 \mathrm{~m}$ high at west end of the landfill site with the surface slope of 2\%, as shown in Figure 5(a). A $60 \mathrm{~m}$-long$\mathrm{DB}$ was located in the center of the model $5 \mathrm{~m}$ above the leachate collection and removal system. The DB was assumed to be backfilled shredded scrap tires with saturated hydraulic 
TABLE 3: Initial conditions used for model validations for the published field studies by Haydar and Khire [8].

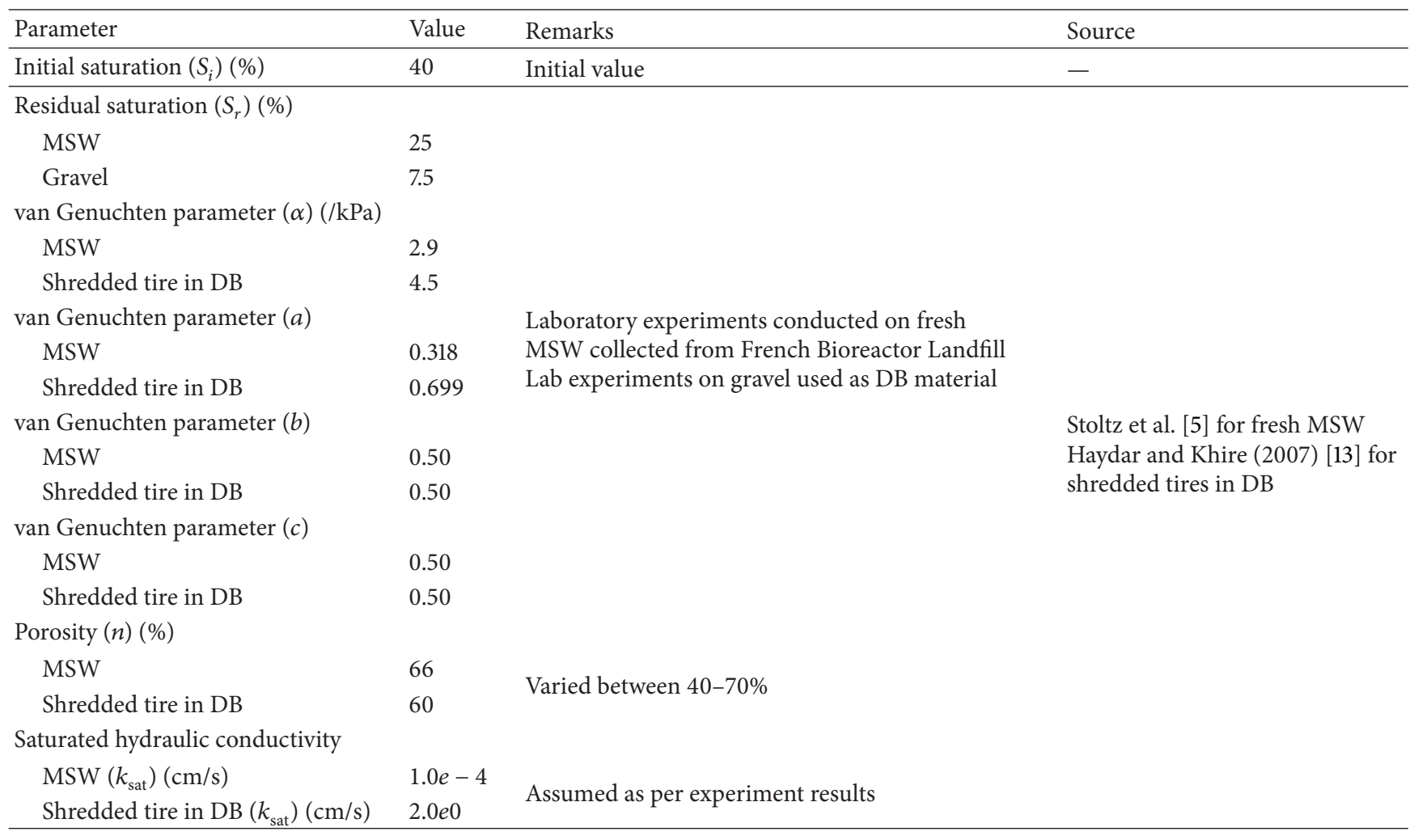

conductivity of $2 \mathrm{~cm} / \mathrm{s}$ placed on the compacted surface of MSW [8]. Based on the grid size analysis, a square grid of $0.3 \mathrm{~m}$ was selected for the analysis of the moisture distribution in landfill. All the boundaries were assumed to be impervious. Any losses in the system including hydraulic losses pertaining to the pipe network and the pumps were not considered. Since Haydar and Khire [8] conducted their field studies during a dry summer period, they did not record precipitation. Therefore, any infiltration of external moisture in the form of rain from the landfill cap was not considered in the FLACbased flow analysis as only the subsurface hydraulics were of interest. The initial model parameters are selected based on published literature and the values are listed in Table 3. The wetted width of MSW within DB only was predicted and compared with the measured results as shown in Figure 5(b).

Since there was no information on the mechanical properties of the MSW material sampled by Haydar and Khire [8], the respective values for fresh MSW are taken from literature [6]. This decision was made as the investigators had reported that the MSW in the field was relatively fresh; these values are summarized in Tables 1 and 3. In addition, as flow only analysis was considered in the original study, the bulk and shear modulus of MSW was adjusted to result in zero deformation during the leachate recirculation period.

Leachate was recirculated through the leachate injection pipe for $20 \mathrm{~min}$ and the moisture migration within DB was monitored [8]. It was found that the injected leachate migrated a distance of $25 \mathrm{~m}$ in the direction of slope due to gravity flow within the DB. A similar situation was modeled in two-phase flow model that resulted in a comparable maximum wetted width of $23.5 \mathrm{~m}$ during $20 \mathrm{~min}$ of leachate injection (Figure 6). The difference of $1.5 \mathrm{~m}$ may be due to the heterogeneous property of shredded tires, a factor that is not considered in this study. However, the error is less than $10 \%$, so the numerical model is able to simulate the Haydar and Khire [8] published study reasonably well.

4.2. Kadambala et al. [9] Study. The development of pore water pressure due to leachate recirculation was monitored at the New River Regional Landfill (NRRL) located in Union County, Florida, USA by Kadambala et al. [9]. Their field observation was carried out in a 7.8 hectare cell equipped with a double liner system, known as Cell 4 . During the testing, the investigators determined that Cell 4 held $20 \mathrm{~m}$ of waste compacted to $700 \mathrm{~kg} / \mathrm{m}^{3}$. The maximum permitted leachate recirculation rate was $122 \mathrm{~m}^{3} /$ day. The saturated hydraulic conductivity of its MSW ranged from $5.4 \times 10^{-6}$ to $6.1 \times 10^{-5} \mathrm{~cm} / \mathrm{s}$. Piezometers were used to measure the water head surrounding the vertical injection wells; the analysis gives pore water pressure in terms of water column head with depth and radially measured with respect to the leachate injection well. For the initial two months, the leachate recirculation was intermittent as it ran for 9 hours every day during the daytime operation hours. In the next stage, leachate recirculation was performed for a four-month period in the injection wells. Finally, continuous leachate injection was performed for 15-20 days for the subsequent two months. The investigators monitored pore pressures in the waste surrounding the wells during and after the leachate 


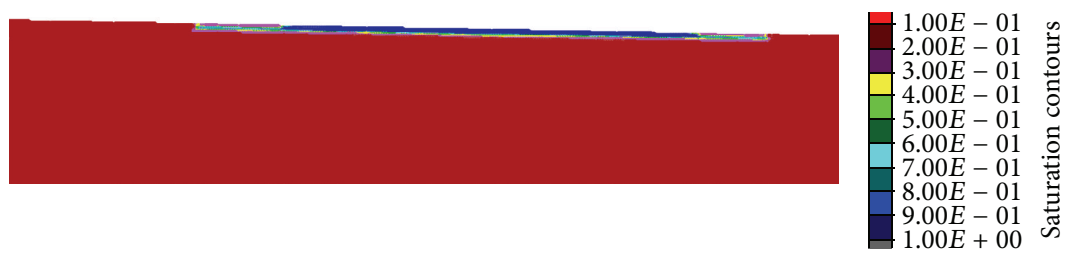

(a)

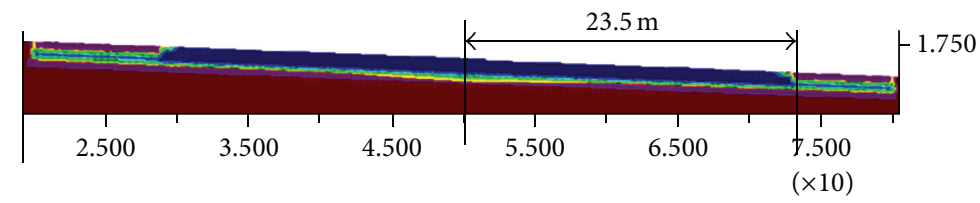

(b)

Figure 6: Maximum distance covered within drainage blanket during 20 minutes of leachate recirculation measured from the leachate injection pipe with respect to saturation greater than $90 \%$.

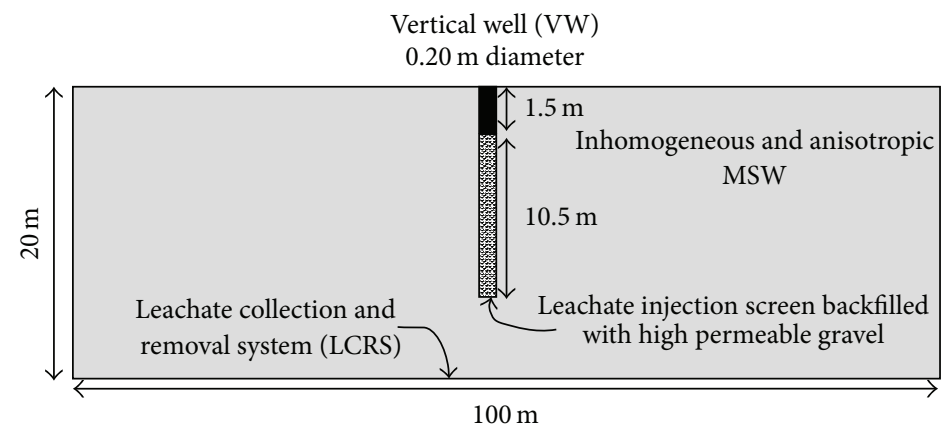

FIGURE 7: Landfill model developed for model validation with Kadambala et al. [9] field study.

recirculation. Approximately 15 to $30 \mathrm{~m}^{3}$ of leachate was recirculated per day. The field observations indicated that the pore water pressure in the waste mass is much less than in or near the injection well (about 50\% less compared to the values found in the injection well and these reduced further with the increase in the depth of landfill).

The two-phase flow modeling simulation of Kadambala et al. [9] used a bioreactor landfill model measuring $100 \mathrm{~m}$ wide by $20 \mathrm{~m}$ high with compacted MSW (Figure 7). A VW measuring $0.2 \mathrm{~m}$ in diameter and $12.0 \mathrm{~m}$ deep with a leachate injection screen starting from $1.5 \mathrm{~m}$ below ground surface (height of leachate injection screen is $10.5 \mathrm{~m}$ ). The intermittent mode of leachate injection was simulated with an injection rate of $15 \mathrm{~m}^{3}$ /day for the initial 2 months for 9 hours daily, approximating the daily operational schedule. Then, a continuous leachate injection at an injection rate of $30 \mathrm{~m}^{3} /$ day was simulated in the successive two months for 20 days on two occasions to result in the cumulative leachate injected into the VW of $1400 \mathrm{~m}^{3}$. The leachate injection screen in the VW was assumed to be backfilled with pea gravel having saturated hydraulic conductivity of $10^{-2} \mathrm{~cm} / \mathrm{s}$, placed on the compacted surface of MSW.

Based on the grid size analysis, the landfill model was discretized using $0.3 \mathrm{~m}$ square grids. All the boundaries of the model were assumed to be impermeable. The initial model parameters are selected from published literature for MSW. Kadambala et al. [9] stated that the MSW saturated hydraulic conductivity ranges from $5.4 \times 10^{-6}$ to $6.1 \times$ $10^{-5} \mathrm{~cm} / \mathrm{s}$ with the apparent bulk unit weight of $700 \mathrm{~kg} / \mathrm{m}^{3}$. Reddy et al. [10] presented a relation between hydraulic conductivity and applied normal pressure and it was used to determine the saturated hydraulic conductivity with depth to represent heterogeneous waste. Further, to represent the field condition [9], the MSW was assumed as anisotropic waste with the horizontal saturated hydraulic conductivity equal to ten times the vertical saturated hydraulic conductivity in each layer. The unsaturated hydraulic properties of MSW reported [5] with the MSW dry unit weight of $5.3 \mathrm{kN} / \mathrm{m}^{3}$ were used. The ranges and final values selected for the model validation are summarized in Table 4 along with the other specific initial parameters. The computed vertical and horizontal saturated hydraulic conductivities for each compacted MSW layer are summarized in Table 5.

Figure 8 compares the measured pore pressure variation with model predictions at different depths and different radial distances from the injection well on day 93. It is clear that the two-phase flow model predicted the pore water pressure with acceptable accuracy with the error less than 
TABLE 4: Initial conditions used for model validation for the published field study by Kadambala et al. [9].

\begin{tabular}{|c|c|c|c|}
\hline Parameter & Value & Remarks & Source \\
\hline \multicolumn{4}{|l|}{ Residual moisture content $\left(\theta_{r}\right)(\%)$} \\
\hline MSW & 20 & \multirow{10}{*}{$\begin{array}{l}\text { (1) Laboratory experiments conducted on } \\
\text { fresh MSW collected from French } \\
\text { Bioreactor Landfill } \\
\text { (2) Laboratory experiments conducted on } \\
\text { gravel }\end{array}$} & \multirow{10}{*}{$\begin{array}{l}\text { (1) Stoltz et al. [5] } \\
\text { (2) Haydar and Khire [12 }\end{array}$} \\
\hline Gravel & 2 & & \\
\hline van Genuchten parameter $(\alpha)(/ \mathrm{kPa})$ & & & \\
\hline MSW & $2.9-5.7(3.5)$ & & \\
\hline Gravel & 5.7 & & \\
\hline van Genuchten parameter $(a)$ & & & \\
\hline MSW & $0.318-0.88(0.55)$ & & \\
\hline Gravel & 0.88 & & \\
\hline van Genuchten parameter $(b)$ & 0.50 & & \\
\hline van Genuchten parameter $(c)$ & 0.50 & & \\
\hline \multicolumn{4}{|l|}{ Porosity $(n)(\%)$} \\
\hline MSW & 68 & \multirow[t]{2}{*}{$40 \%$ to $80 \%$ Typical } & \multirow[t]{2}{*}{ Variable for (MSW) } \\
\hline Gravel & 47 & & \\
\hline \multicolumn{2}{|c|}{ Saturated hydraulic conductivity $\left(k_{\text {sat }}\right)(\mathrm{cm} / \mathrm{s})$} & \multirow{3}{*}{$\begin{array}{l}\text { Laboratory tests conducted on fresh } \\
\text { MSW from bioreactor landfill in USA }\end{array}$} & \multirow{3}{*}{$\begin{array}{l}\text { Reddy et al. [10] } \\
\text { Haydar and Khire [12] }\end{array}$} \\
\hline MSW & Table 5 & & \\
\hline Gravel & $1.0 \times 10^{-2}$ & & \\
\hline
\end{tabular}

TABLE 5: Saturated hydraulic conductivity for heterogeneous anisotropic MSW used for model validation for the published field study by Kadambala et al. [9].

\begin{tabular}{lcc}
\hline Layer & $\begin{array}{c}\text { Vertical saturated } \\
\text { hydraulic conductivity } \\
\left(k_{V}\right)(\mathrm{cm} / \mathrm{s})\end{array}$ & $\begin{array}{c}\text { Horizontal saturated } \\
\text { hydraulic conductivity } \\
\left(k_{h}\right)(\mathrm{cm} / \mathrm{s})\end{array}$ \\
\hline 10 & $6.1 E-05$ & $6.1 E-04$ \\
9 & $5.4 E-05$ & $5.4 E-04$ \\
8 & $2.7 E-05$ & $2.7 E-04$ \\
7 & $1.6 E-05$ & $1.6 E-04$ \\
6 & $1.0 E-06$ & $1.0 E-05$ \\
5 & $9.6 E-06$ & $9.6 E-05$ \\
4 & $7.6 E-06$ & $7.6 E-05$ \\
3 & $6.3 E-06$ & $6.3 E-05$ \\
2 & $5.8 E-06$ & $5.8 E-05$ \\
1 & $5.4 E-06$ & $5.4 E-05$ \\
\hline
\end{tabular}

${ }^{*}$ Normal pressure is calculated with MSW layer thickness $=2.0 \mathrm{~m}, 10$ layers in total.

approximately $10 \%$. For instance, the pore water pressure measured in the field at a point located at $11.9 \mathrm{~m}$ depth from the ground surface presented a reading of about $17.5 \mathrm{~m}$ of water column (W.C.), while the simulations predicted a pore water pressure at the same point of about $19.13 \mathrm{~m}$ of W.C. Field observations indicated minor fluctuations in the pore water pressure readings that demonstrated the decrease in pore water pressure in relation to the increase in radial distance from the leachate injection well. The two-phase flow model identifies a similar trend. Further, because the MSW is heterogeneous and anisotropic, it possesses lower saturated hydraulic conductivity in the deeper layers. This leads to higher pore water pressure values when compared to those values that are found in the shallow layers through both the field observations and the simulation. Pore water pressures, when compared as a function of depth at different radial distances, show that the pressure values are higher near the leachate injection screen and decrease with the increase in the radial distance from that screen (Figure 9). For instance, the pore pressure values measured in terms of water column in the piezometer at a radial distance of $2.15 \mathrm{~m}$ from the injection well indicates about $9.0 \mathrm{~m}$ of W.C. in the field; the two-phase flow model result was $10.6 \mathrm{~m}$ of W.C. The field study does not include a few data points. This may be due to the inadequacy of the measuring instruments at that location. However, these missing values can be estimated accurately in the two-phase 


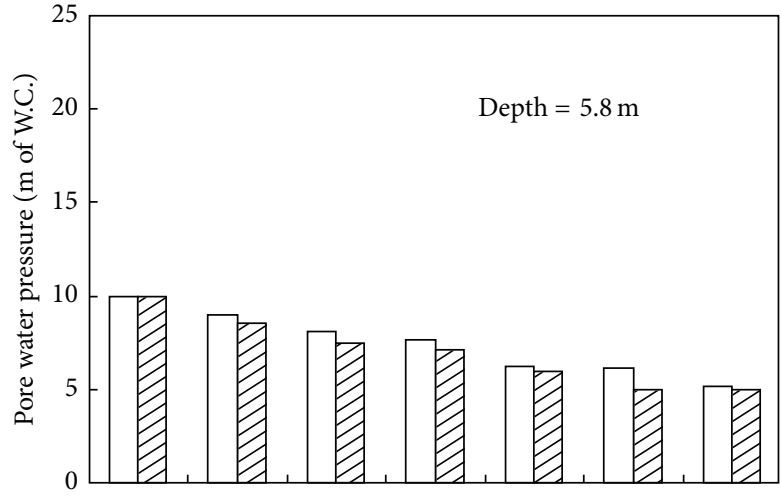

(a)

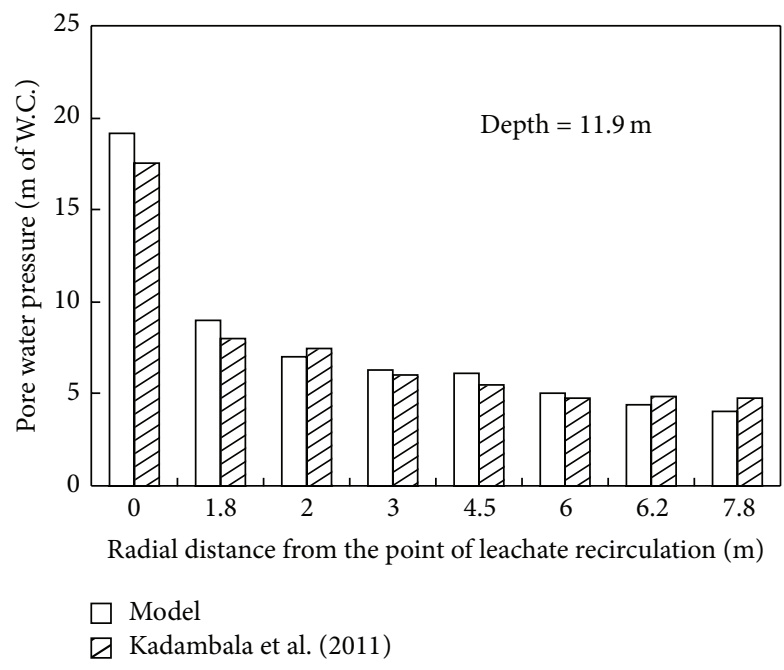

(c)

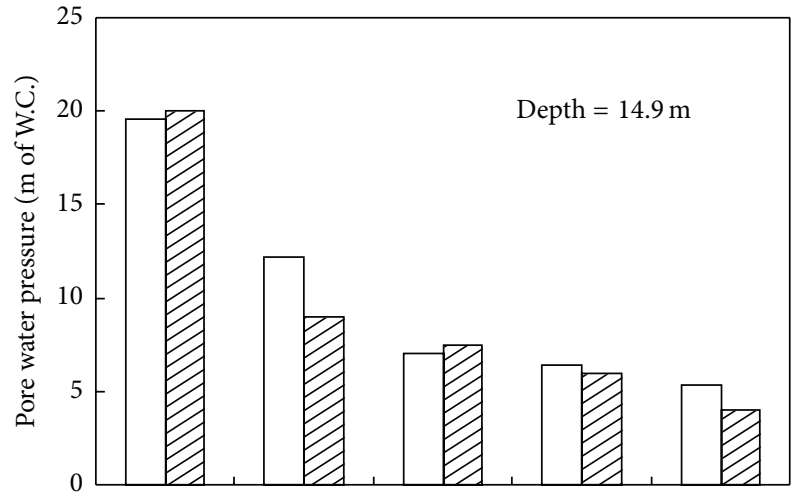

(b)

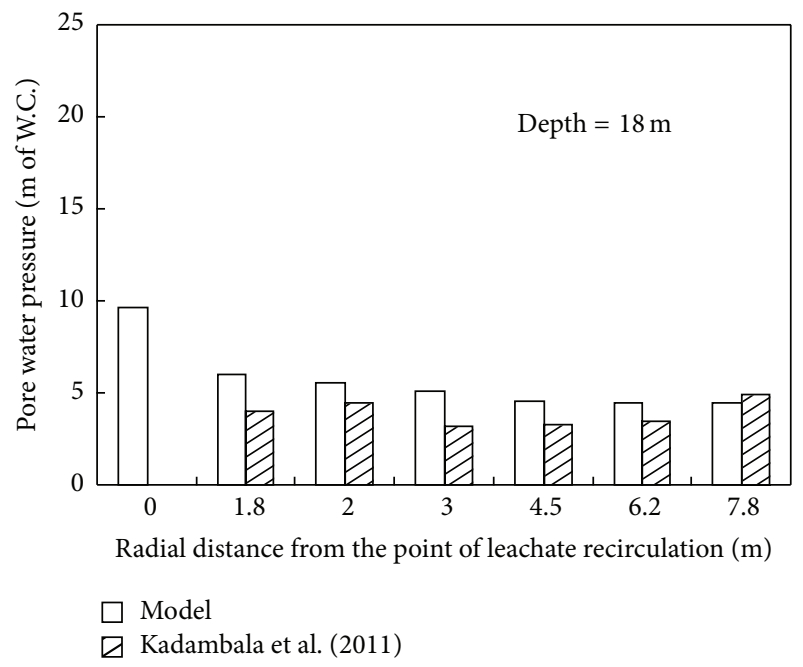

(d)

FIGURE 8: Comparison of pore pressure variation with the published field study by Kadambala et al. [9] in the waste surrounding the injection well as a function of radial distance on day 93 at different depths.

flow model. Overall, the mathematical model implemented in this study has predicted results that are comparable to the field observations with considerable accuracy.

\section{Validation with Modeling Studies}

5.1. McCreanor [11] Study. McCreanor [11] investigated leachate routing in a bioreactor landfill using the mathematical model SUTRA-saturated and unsaturated flow and transport-developed by United States Geological Survey (USGS), which is a hybrid finite element and finite differencebased model designed to analyze flow, density, and transport in porous media. The investigator simulated leachate routing in MSW by implementing both horizontal trenches (HT) and vertical wells (VW) as leachate recirculation systems. A conceptual landfill model was selected for the HT and VW evaluations with landfill cell measuring $16 \mathrm{~m}$ wide and $15 \mathrm{~m}$ in height (Figure 10(a)). The HT was located at a point $8 \mathrm{~m}$ above the leachate recirculation system and is described as $2 \mathrm{~m}$ wide and $0.6 \mathrm{~m}$ deep. This study investigated the effects of the leachate application rate $\left(2,4\right.$ and $\left.8 \mathrm{~m}^{3} / \mathrm{day} / \mathrm{m}\right)$, saturated hydraulic conductivity $\left(10^{-3}, 10^{-4}\right.$ and $\left.10^{-5} \mathrm{~cm} / \mathrm{s}\right)$, and mode of leachate application (continuous and intermittent) on moisture distribution for one week of operation.

The VW was simulated assuming the leachate was injected in to a well measuring $1.2 \mathrm{~m}$ in diameter with an injection screen located $13 \mathrm{~m}$ above the leachate collection system (LCS). It analyzed the effect of leachate application rate $\left(5,10,15,20,30\right.$, and $60 \mathrm{~m}^{3} /$ day $)$, saturated hydraulic conductivity $\left(10^{-3}, 10^{-4}\right.$, and $\left.10^{-5} \mathrm{~cm} / \mathrm{s}\right)$, and mode of leachate application (continuous and intermittent) on the moisture distribution for three weeks.

The effect of daily cover material, anisotropic property of MSW, and stochastic approach on moisture distribution in a bioreactor landfill cell are assumed. The effect of anisotropy was analyzed assuming the horizontal hydraulic conductivity varying ten times the vertical hydraulic conductivity and the stochastic modeling was performed to simulate the heterogeneous MSW implementing probability density function, for hydraulic conductivity variation. MSW was considered as a single layer with the respective average values. Although the SUTRA model has the capability of simulating unsaturated 


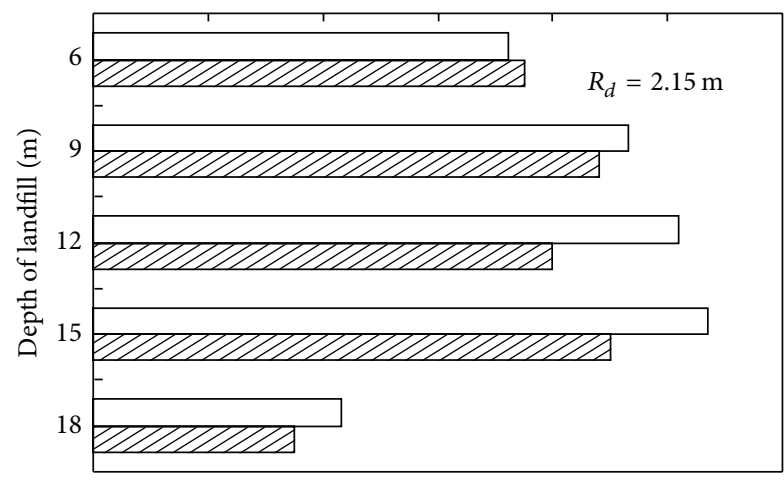

(a)

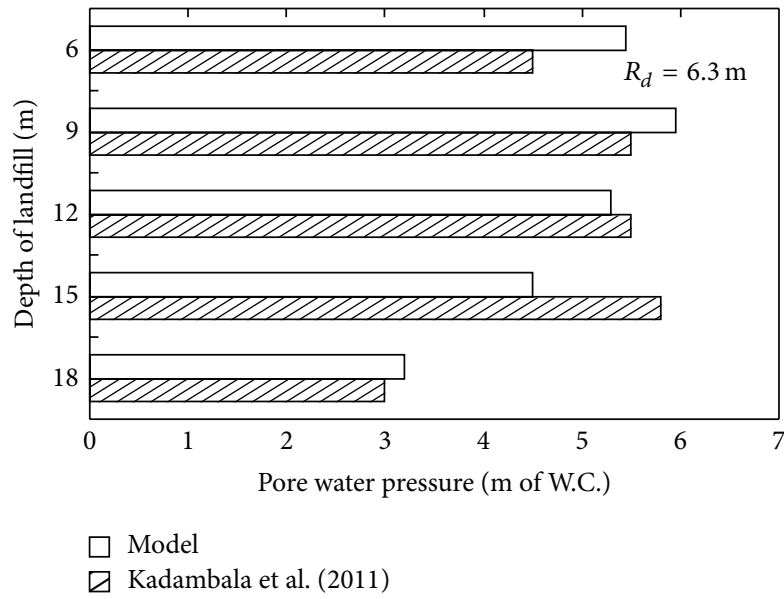

(c)

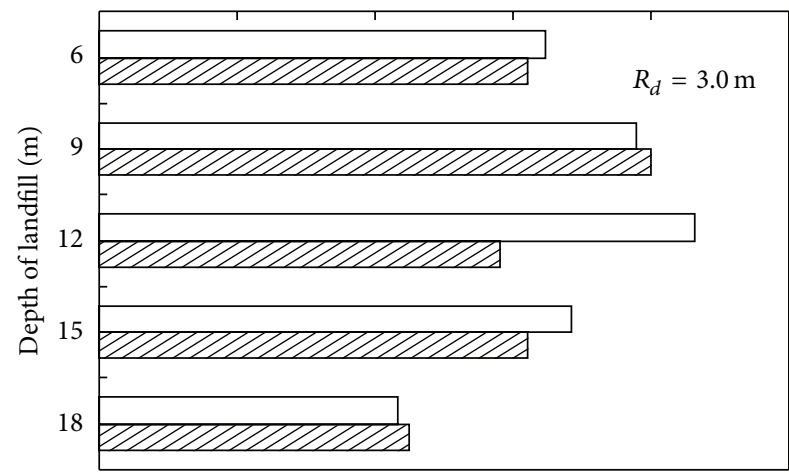

(b)

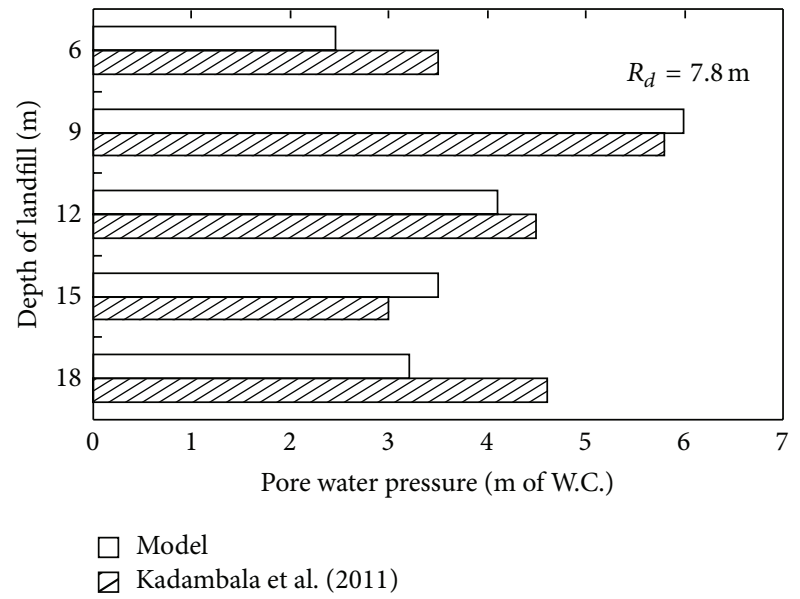

(d)

FIGURE 9: Comparison of pore pressure variation with the published field study by Kadambala et al. [9] in the waste surrounding the injection well as a function of depth on day 93 at different radial distance.

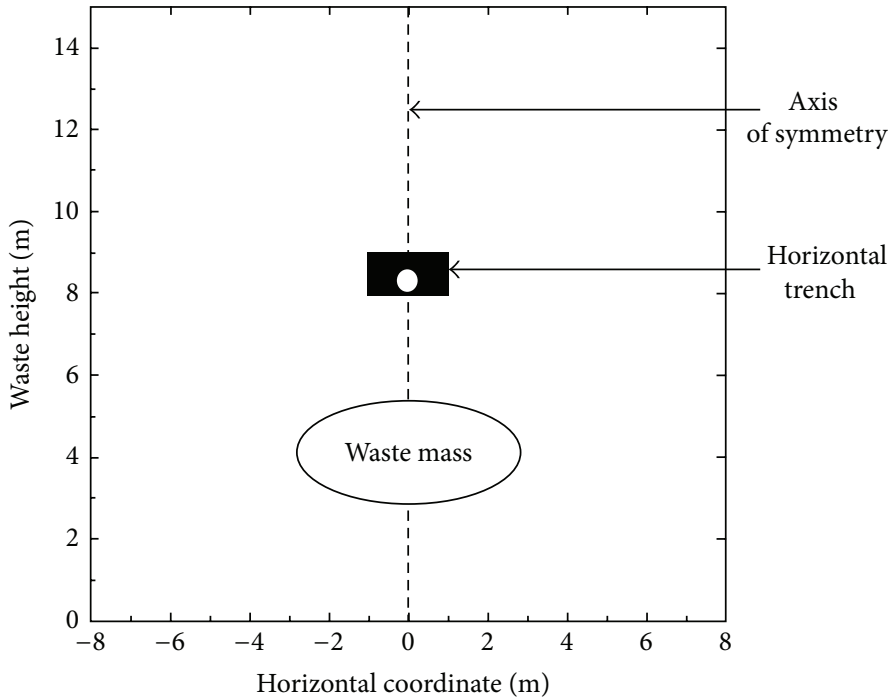

(a)

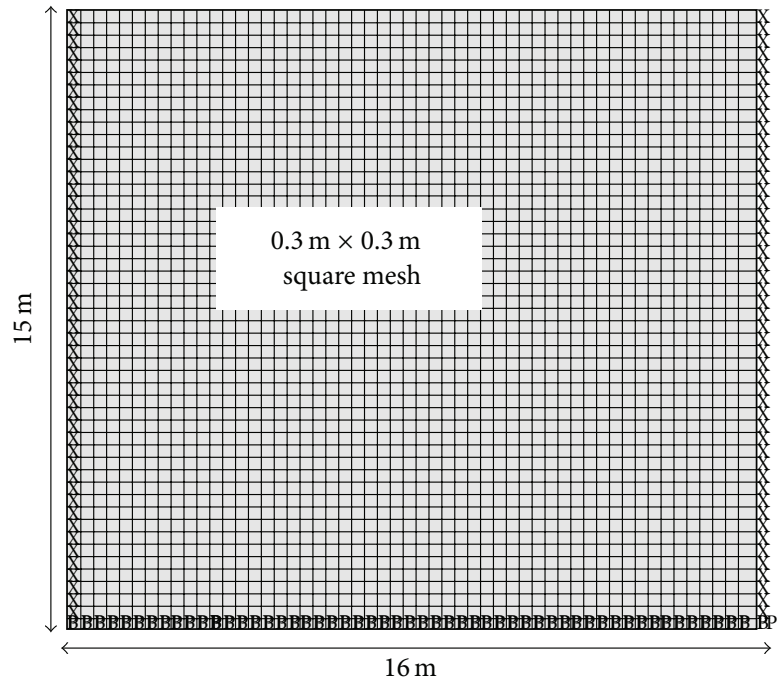

(b)

FIgURE 10: (a) Conceptual model for HT developed by (McCreanor, [11]); (b) model discretization for two-phase flow model (in this study). 
porous media, McCreanor [11] performed simulations considering the single phase leachate flow analysis.

5.1.1. Horizontal Trench System Modeling. The conceptual model for HT developed by McCreanor [11] consists of a bioreactor landfill cell of $16 \mathrm{~m}$ wide and $15 \mathrm{~m}$ in height (Figure 10(a)) where the MSW was considered as single homogeneous layer. The HT was located $8 \mathrm{~m}$ above the leachate collection system (LCS). It is $2 \mathrm{~m}$ wide and $1 \mathrm{~m}$ high, backfilled with high permeability material with a porosity of 0.3 , and saturated hydraulic conductivity of $10^{-1} \mathrm{~cm} / \mathrm{s}$. The leachate was injected in to the HT using application rates of 2 , 4 , and $8 \mathrm{~m}^{3} /$ day $/ \mathrm{m}$ length of trench for a period of one week. The results of the one week continuous application were compared with the results from an intermittent leachate application that was operational for $8 \mathrm{hr}$ and then turned off for $16 \mathrm{hr}$ for a period of one week. The lateral movement and upward movement of the leachate with respect to different application rates and saturated hydraulic conductivities were determined.

Two-phase flow modeling using FLAC followed the conceptual SUTRA model ( $15 \mathrm{~m}$ in height and $16 \mathrm{~m}$ wide) used by McCreanor [11]. Based on the grid size analysis, this model is discretized by $0.3 \mathrm{~m}$ square grids (Figure 10(b)). The model is fixed for zero deformations in lateral and vertical direction at the bottom of the landfill cell, and lateral deformations on sides of the landfill cell are fixed to zero deformation since the simulations are performed only for the flow calculations. Hydraulic boundary conditions consist of permeability and the pore water pressure development in the model. By default, all boundaries are considered to be impermeable. The pore water pressure is fixed to zero at the bottom of the landfill cell and the leachate outflow rate is computed. A HT of $2 \mathrm{~m}$ wide and $1 \mathrm{~m}$ deep is considered to be backfilled with high permeable possessing porosity of 0.3 and saturated hydraulic conductivity of $10^{-1} \mathrm{~cm} / \mathrm{s}$.

The general model parameters that are constant for all the model simulations are summarized in Table 1. The specific initial condition parameters to simulate the HT for the FLAC model validation implementing the two-phase flow analysis in an unsaturated MSW are summarized in Table 1. These properties are selected to represent the MSW and the respective values are obtained from the sources as identified in Table 1. The initial pore water pressures of wetting and nonwetting fluids were assumed as zero at all grid points. The wetting and nonwetting fluid bulk moduli assumed are the typical values for water and air to appropriately represent leachate and landfill gas, respectively. The van Genuchten fitting parameters (residual saturation, saturated moisture content, matric suction, and fitting parameters " $a$ ", " $b$ ", " $c$," and " $P_{0}$ ") are selected from previous studies [5]. Though the composition of the MSW tested by Stoltz et al. [5] was different from the MSW in the Florida landfill, the MSW in both studies is about 2 to 3 years old, and the hydraulic properties are assumed to be similar. The coefficient for the pore water pressure increment due to the volumetric strain was assumed as zero to represent flow only calculations. The initial porosity of the MSW was varied from $40 \%$ to $70 \%$ and, after calibration, the porosity of $66 \%$ was selected (Table 1 ). Simulations are performed for different saturated hydraulic conductivities $10^{-3}, 10^{-4}$, and $10^{-5} \mathrm{~cm} / \mathrm{s}$ with different leachate injection rates of 2,4 , and $8 \mathrm{~m}^{3} / \mathrm{day} / \mathrm{m}$ length of trench. The unit density of the MSW was $1152 \mathrm{~kg} / \mathrm{m}^{3}$ and the saturated moisture content of the MSW is $66 \%$ on volumetric basis.

Figure 11 shows the comparison of the lateral and upward movement of the injected leachate for the different leachate application rates with varying saturated hydraulic conductivity obtained from the FLAC and SUTRA models after the leachate was injected continuously for one week. The saturation isoclines for the three saturated hydraulic conductivities $\left(10^{-3}, 10^{-4}\right.$, and $\left.10^{-5} \mathrm{~cm} / \mathrm{s}\right)$ with leachate application rate of $4 \mathrm{~m}^{3} /$ day/m length of trench are compared in Figure 5.1.1. These results show that the FLAC model results are in close agreement with SUTRA model results in terms of lateral movement, upward movement, and the saturation levels and isoclines shapes.

The results of the model simulations are compared for intermittent injection ( $8 \mathrm{hrs}$ on followed by $16 \mathrm{hrs}$ off) as plotted in Figure 13 for the different saturated hydraulic conductivity of MSW and leachate injection rates. It is interesting to note that the lateral movement and the upward movement of the injected leachate obtained by FLAC simulation differ from the lateral and upward movement predicted with the SUTRA model by McCreanor [11]. Under the intermittent leachate injection operation, both the lateral movement and upward movement should be less than that when the leachate is continuously recirculated (Figures 5.1.1 and 13). Yet, McCreanor [11] reports that the lateral movement and the upward movement were either the same or even greater than in the scenario where the leachate was injected continuously (Figure 13). For example, the SUTRA model simulated the lateral movement for the leachate injection rate of $4 \mathrm{~m}^{3} / \mathrm{d} / \mathrm{m}$ with saturated hydraulic conductivity of $10^{-4} \mathrm{~cm} / \mathrm{s}$ as $2.8 \mathrm{~m}$ under continuous leachate injection and $3.5 \mathrm{~m}$ under intermittent leachate injection, which is contradictory. Since the leachate injection was stopped for 16 hours before starting the successive injection, the lateral movement will be less when compared to the continuous leachate injection operation. This is observed in the results from the FLAC model (Figure 13), where the lateral movement was $3.0 \mathrm{~m}$ under continuous leachate injection and $2.7 \mathrm{~m}$ under intermittent leachate injection for the leachate injection rate of $4 \mathrm{~m}^{3} / \mathrm{d} / \mathrm{m}$ with saturated hydraulic conductivity of $10^{-4} \mathrm{~cm} / \mathrm{s}$, which seems reasonable. The unsaturated hydraulic properties of MSW may also affect these results, so this needs investigation and evaluation in the future. Figure 14 compares the saturation isoclines produced by the two models; the shape and the saturation levels are similar although the lateral and upward movement values are not. It is also evident from Figure 15 that the lateral and upward movement is dependent on the mode of leachate injection. While there is room for some interesting future research, overall, the results from the FLAC model are comparable to those produced by McCreanor [11] using the SUTRA model, proving the applicability of the twophase FLAC model. 

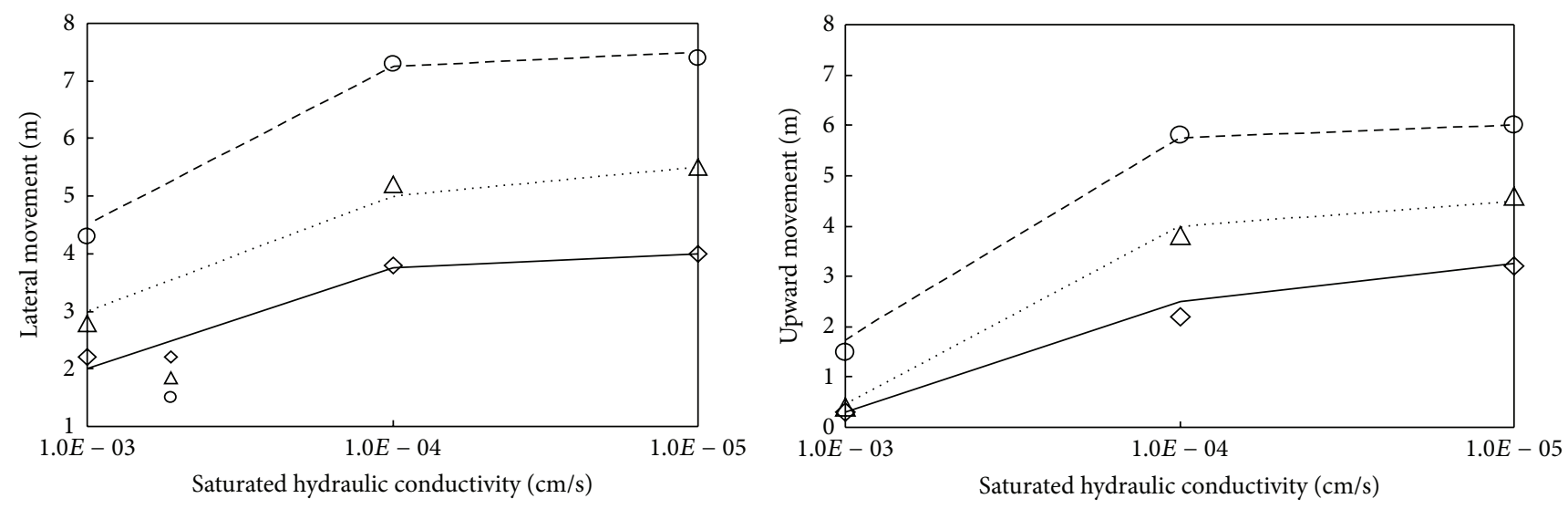

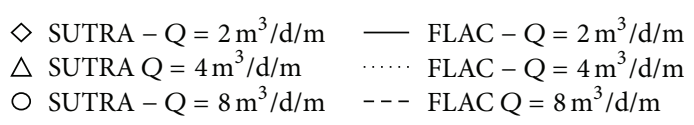

(a)

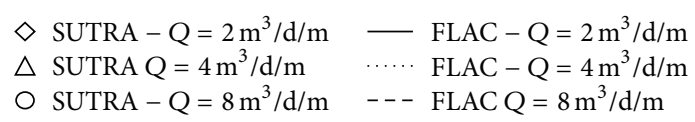

(b)

FIGURE 11: Lateral and upward movement versus saturated hydraulic conductivity of MSW for continuous leachate recirculation for one week period.

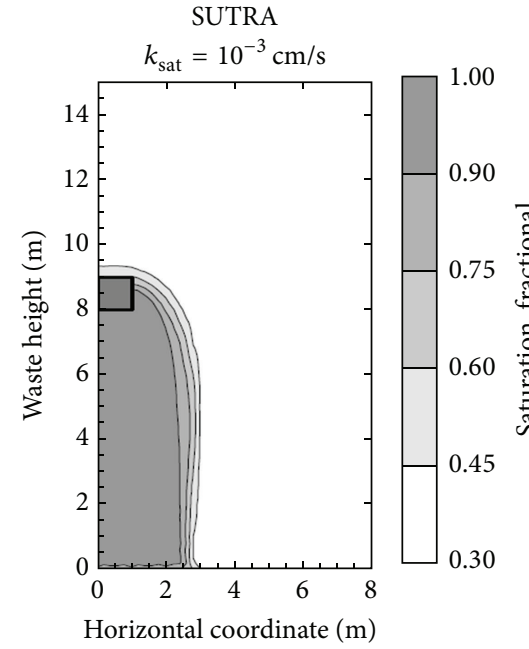

(a)

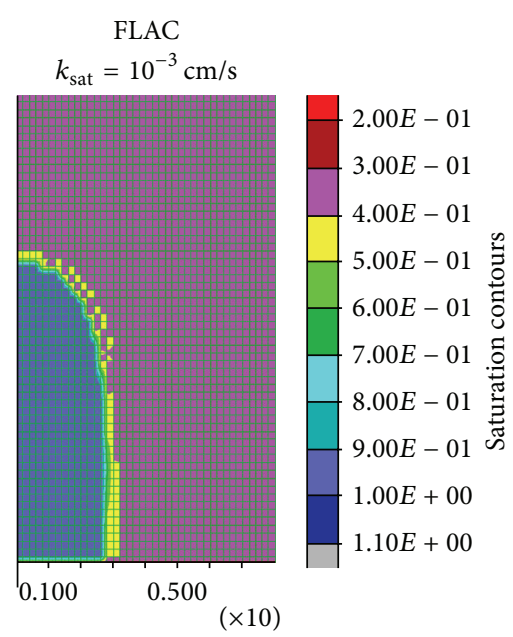

(b)

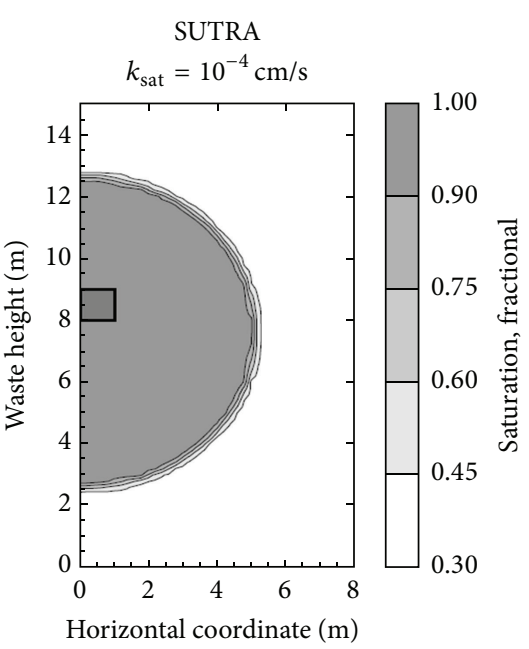

(c)

SUTRA

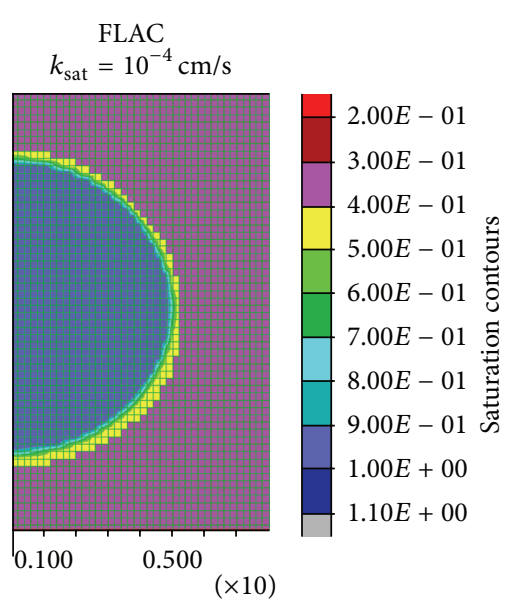

(d)

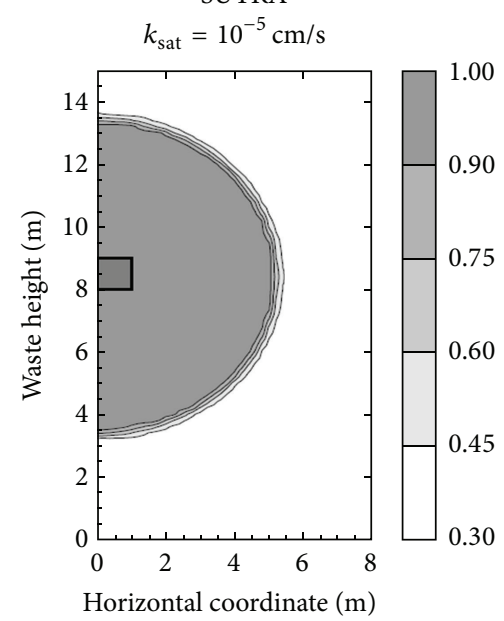

(e)

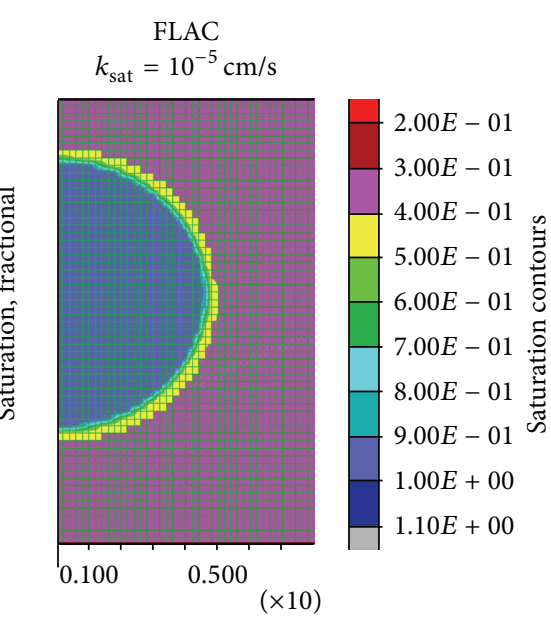

(f)

FIGURE 12: Saturation isoclines for HT operated continuously at rate of $4 \mathrm{~m}^{3} /$ day/m after one week flow. 


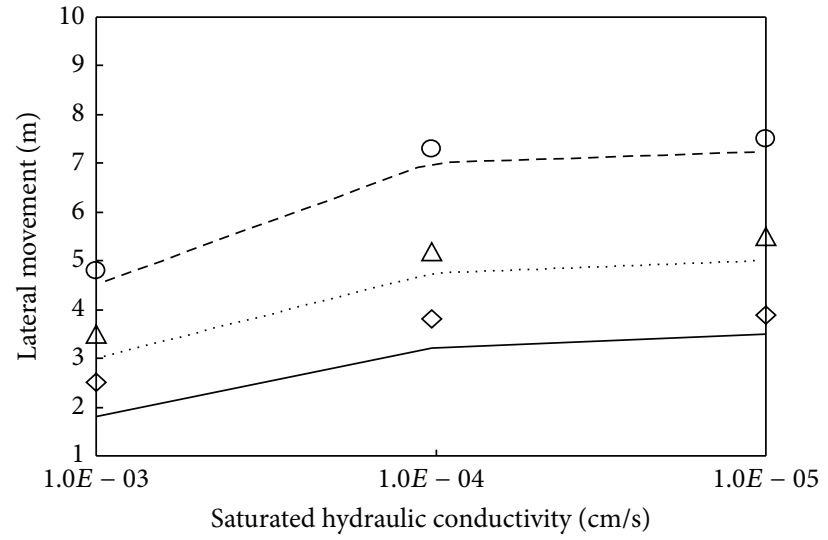
$\diamond$ SUTRA $-\mathrm{Q}=2 \mathrm{~m}^{3} / \mathrm{d} / \mathrm{m} \longrightarrow$ FLAC $-\mathrm{Q}=2 \mathrm{~m}^{3} / \mathrm{d} / \mathrm{m}$
$\triangle$ SUTRA $Q=4 \mathrm{~m}^{3} / \mathrm{d} / \mathrm{m} \quad \cdots .$. FLAC $-Q=4 \mathrm{~m}^{3} / \mathrm{d} / \mathrm{m}$
O SUTRA $-Q=8 \mathrm{~m}^{3} / \mathrm{d} / \mathrm{m} \quad--$ FLAC $Q=8 \mathrm{~m}^{3} / \mathrm{d} / \mathrm{m}$

(a)

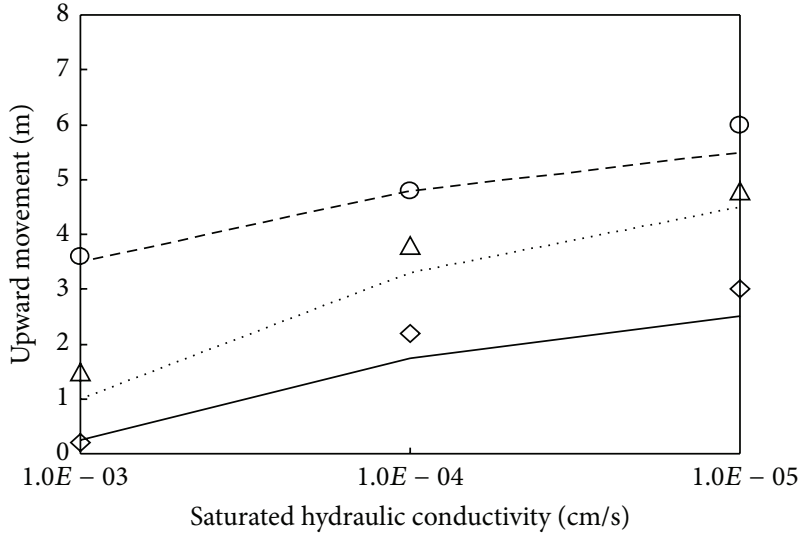
$\diamond$ SUTRA $-\mathrm{Q}=2 \mathrm{~m}^{3} / \mathrm{d} / \mathrm{m} \longrightarrow$ FLAC $-\mathrm{Q}=2 \mathrm{~m}^{3} / \mathrm{d} / \mathrm{m}$
$\triangle$ SUTRA $Q=4 \mathrm{~m}^{3} / \mathrm{d} / \mathrm{m}$
SUTRA $-Q=8 \mathrm{~m}^{3} / \mathrm{d} / \mathrm{m}$
.... FLAC $-\mathrm{Q}=4 \mathrm{~m}^{3} / \mathrm{d} / \mathrm{m}$
- - $\quad$ FLAC $Q=8 \mathrm{~m}^{3} / \mathrm{d} / \mathrm{m}$

(b)

FIGURE 13: Lateral and upward movement versus saturated hydraulic conductivity of MSW for intermittent leachate recirculation with 8 hrs on and $16 \mathrm{hrs}$ off, for one week period.

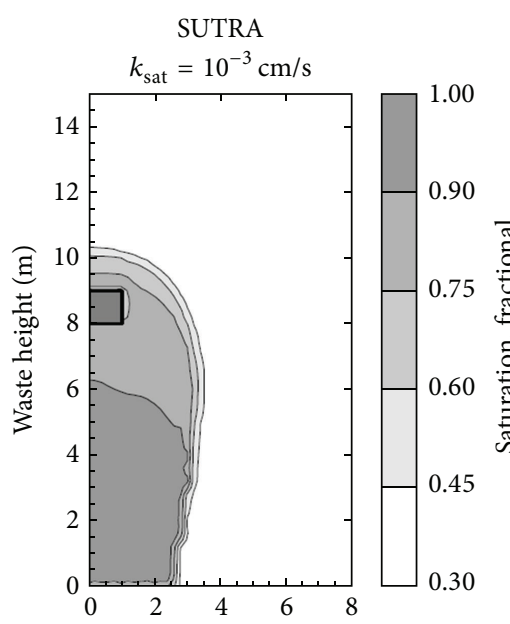

Horizontal coordinate $(\mathrm{m})$

(a)

FLAC

$$
k_{\text {sat }}=10^{-4} \mathrm{~cm} / \mathrm{s}
$$

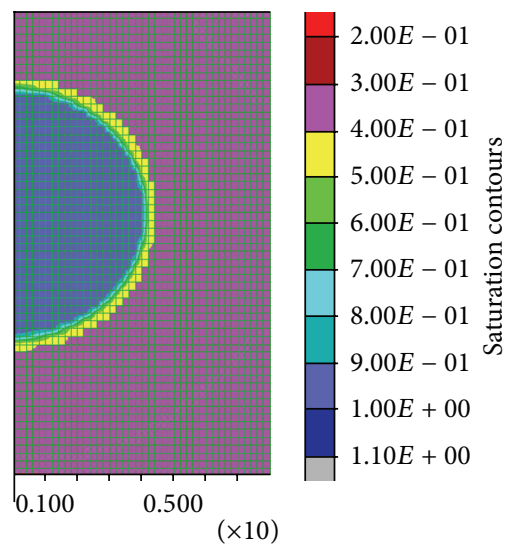

(d)

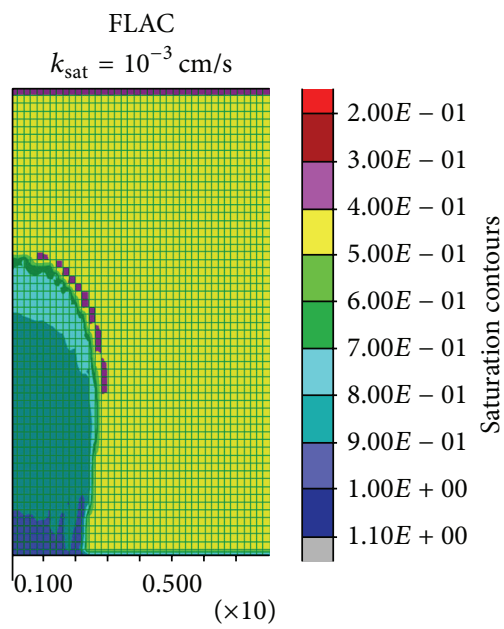

(b)

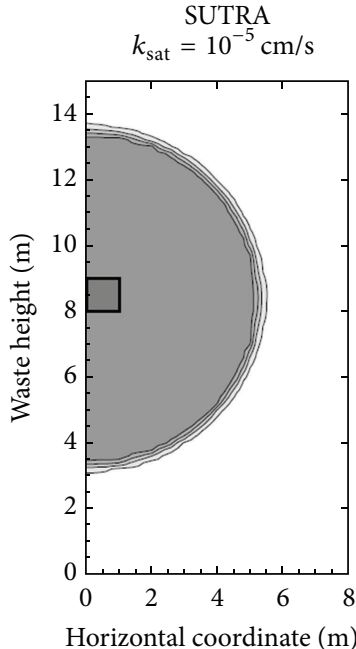

(e)

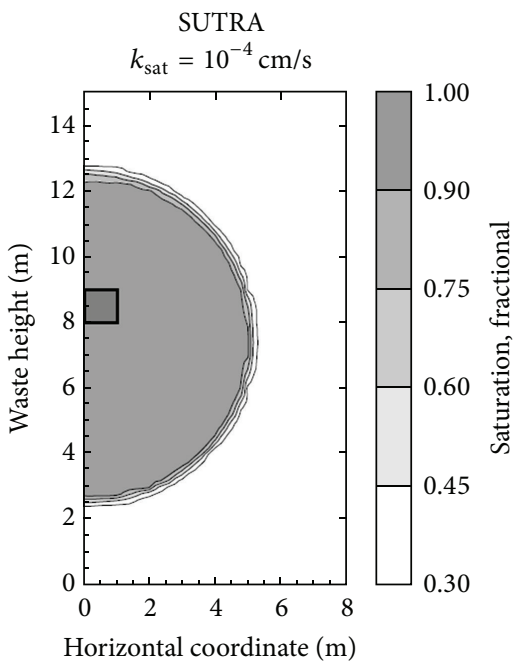

(c)

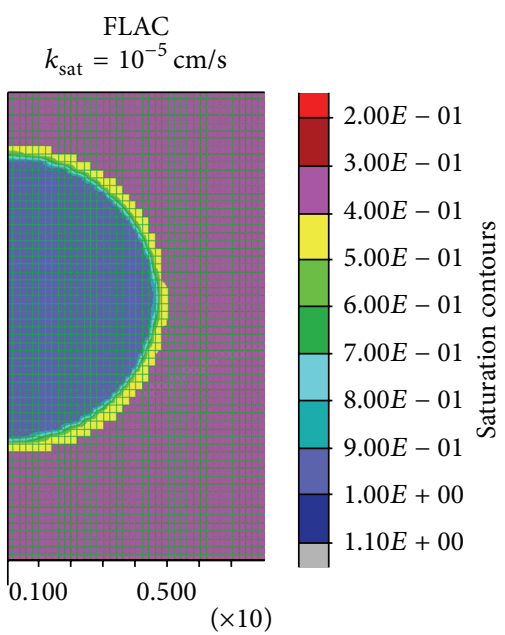

(f)

FIGURE 14: Saturation isoclines for HT operated intermittently at rate of $4 \mathrm{~m}^{3} /$ day/m after one week flow. 


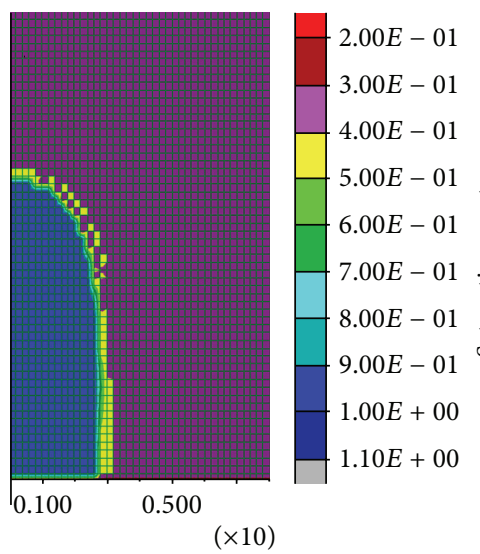

(a)

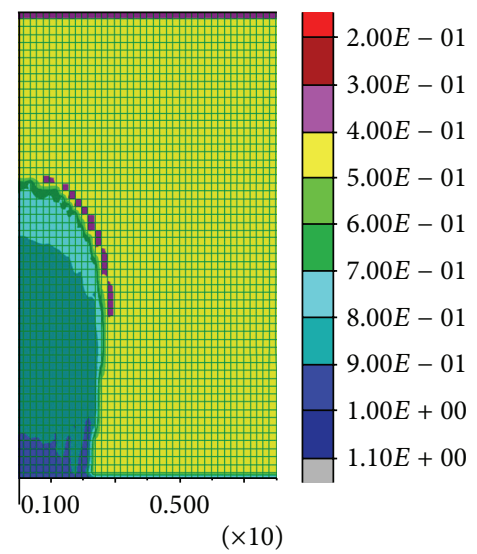

(b)

FIGURE 15: Comparison of saturation isoclines for continuous and intermittent leachate injection at rate of $4 \mathrm{~m}^{3} / \mathrm{day} / \mathrm{m}$ with permeability $10^{-3} \mathrm{~cm} / \mathrm{s}$ for one week flow.

5.1.2. Vertical Well System Modeling. McCreanor [11] also simulated the leachate recirculation in a bioreactor landfill using VW as leachate recirculation system following the same conceptual landfill model as described above for the HT (Figure 10). The VW diameter assumed was $1.2 \mathrm{~m}$ with the VW injection screen extending from $13 \mathrm{~m}$ above the LCS down to the LCS. McCreanor [11] explains the method for calculating the leachate injection rate assigned at each node assuming the liquid pressure would increase at the bottom most nodes (Figure 16). In this model, the MSW was considered as homogeneous and isotropic. The injection screen backfill material consisted of highly permeable material with saturated hydraulic conductivity of $10^{-2} \mathrm{~cm} / \mathrm{s}$. Leachate was injected into the VW at a rate of 5, 10, 15, 20, 30, and $60 \mathrm{~m}^{3} /$ day. The effect of the leachate injection rate and saturated hydraulic conductivity $\left(10^{-3}, 10^{-4}\right.$, and $\left.10^{-5} \mathrm{~cm} / \mathrm{s}\right)$ on the lateral width of the injected leachate was evaluated. Furthermore, the study simulated the effects of continuous and intermittent leachate injection on moisture distribution. The lateral movement and vertical upward movement of the injected leachate for the six different leachate injection rates and saturated hydraulic conductivity were presented. One finding demonstrated that the increase in lateral movement of the leachate with the respective increase in application rate and time of leachate injection. Saturation isoclines were compared for the different hydraulic conductivity levels after the leachate was injected into the $\mathrm{VW}$ at a rate of $10 \mathrm{~m}^{3} /$ day continuously for three weeks. The investigator extended the model simulations for the intermittent leachate application ( $8 \mathrm{hr}$ on and $16 \mathrm{hr}$ off) so that it operated for three weeks rather than one week. Along the same lines, the results also presented the lateral and upward movement of the injected leachate by varying the saturated hydraulic conductivity and leachate injection rate. The study concluded that the lower the hydraulic conductivity, the higher the level of lateral movement and saturation level in the system. Interestingly but contrary to expectation, McCreanor [11] also shows that

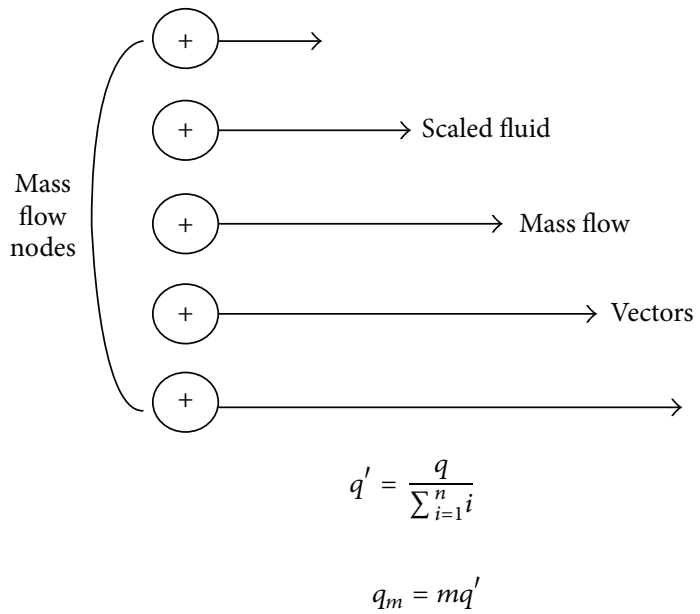

$q^{\prime}$ : Incremental flow unit, MT-1

$q^{\prime}$ : Total flow to well, MT-1

$n$ : Number of nodes used to simulate the well flow

$i$ : Integer

$q_{m}$ : Fluid flow at node $m$, MT-1

$m$ : Node number

Figure 16: Flux nodes to simulate VW by McCreanor [13].

the lateral movement is greater when the leachate injection is intermittent than when it is applied continuously.

A landfill model of $15 \mathrm{~m}$ high and $16 \mathrm{~m}$ wide was selected for the FLAC model simulation with VW as leachate recirculation system (Figure 10). The boundary conditions that consist of mechanical and hydraulic conditions are the same as those assumed for the study of the HT. The model was fixed for zero deformations in both lateral and vertical deformations at the bottom and the lateral deformations were 


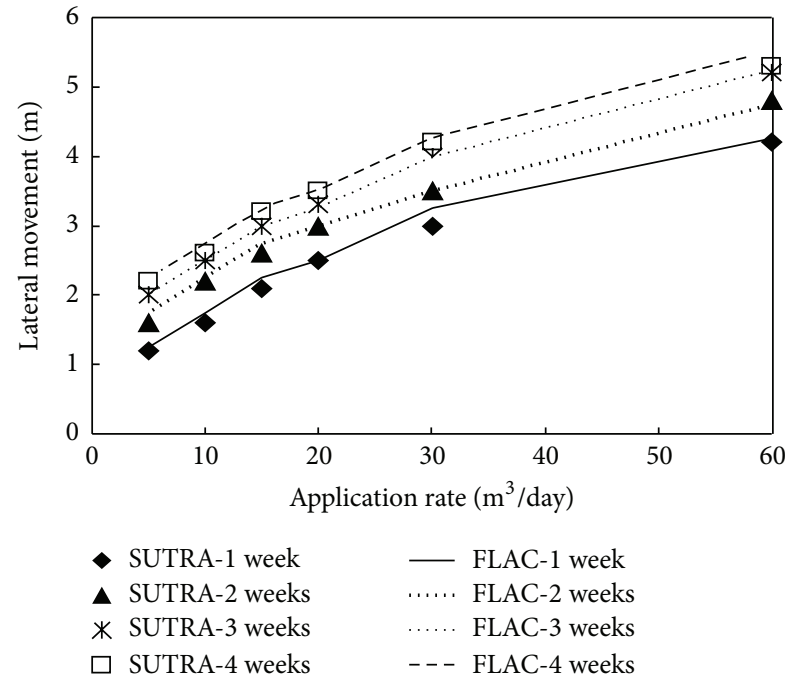

(a)

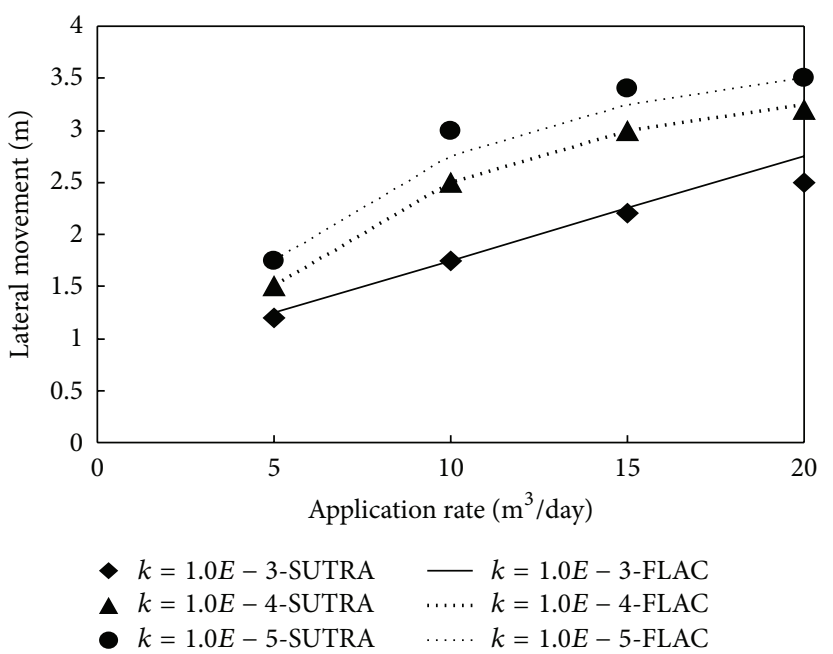

(b)

FIGURE 17: Lateral movement versus application rate for (a) continuous recirculation for one week with MSW ksat $=10^{-3} \mathrm{~cm} / \mathrm{s}$ and; $(\mathrm{b})$ saturated hydraulic conductivity for one week continuous flow.

set to zero in the sides of the model. As far as the hydraulic boundary conditions are concerned, the permeability at all boundaries was set at zero, and the initial pore water pressure at all nodes was set at zero. To avoid leachate accumulation in the LCS, the bottom most nodes are fixed for zero pore water pressure. A VW of $1.2 \mathrm{~m}$ wide and $13 \mathrm{~m}$ deep was considered and assumed to be backfilled with highly permeable gravel possessing porosity of 0.3 and saturated hydraulic conductivity of $10^{-1} \mathrm{~cm} / \mathrm{s}$.

The general initial conditions are summarized in Table 1, and the specific initial conditions for the VW system were same as that implemented in case of HT. The respective initial condition parameters assumed are summarized in Table 1. The grid point variables are initial pore water pressure, wetting and nonwetting fluid bulk modulus, unsaturated hydraulic properties (van Genuchten fitting parameters, $a, b$, and $c$ and $P_{0}$ ), and the zone variables are saturated hydraulic conductivity (varied as $10^{-3}, 10^{-4}$, and $10^{-5} \mathrm{~cm} / \mathrm{s}$ ), and initial porosity. The selected saturated moisture content of the MSW is $66 \%$ on volumetric basis, and the unit weight of the MSW assumed is $1152 \mathrm{~kg} / \mathrm{m}^{3}$.

Leachate recirculation in a VW was evaluated by McCreanor [11], using the conceptual SUTRA model, as either operated continuously or intermittently for duration of three to four weeks. Intermittent leachate recirculation was being simulated as having been injected continuously for $8 \mathrm{hrs}$ followed by a 16-hour stoppage or hiatus in the leachate application. Figure 17 shows the lateral movement simulated by FLAC and compares it to the values derived by simulations using the SUTRA model where the system was operated for four weeks with the leachate applied continuously and where the MSW saturated hydraulic conductivity is $10^{-3} \mathrm{~cm} / \mathrm{s}$. Evidently, the lateral movement simulated by FLAC follows the trends and the values produced by the SUTRA model very closely. This finds that the higher the leachate application rate, the higher the wetted width of the injected leachate, and it also showed that the lateral width of the injected leachate increased with the increase in length of application time.

During the first week flow, the lateral movement of injected leachate increased with a decrease in saturated hydraulic conductivity. For example, for an application rate of $5 \mathrm{~m}^{3} /$ day, the simulated lateral widths are $2.2,2.5$, and $3.0 \mathrm{~m}$ for saturated hydraulic conductivity of $10^{-3}, 10^{-4}$, and $10^{-5} \mathrm{~cm} / \mathrm{s}$, respectively (Figure 17). McCreanor [11] also found similar results for the effect of saturated hydraulic conductivity. Furthermore, when the leachate injection is continued for two and three weeks, the lateral width increased with the decrease in saturated hydraulic conductivity and increase in leachate application time. Saturation isoclines (Figure 18) also indicate that the saturation level increased in the MSW with decrease in saturated hydraulic conductivity. Since the decrease in the size of the pores reduces the vertical movement of the injected leachate, the pore water or leachate applied to the MSW is not allowed to migrate, raising the saturation level in the MSW and commensurately increasing the lateral movement of the leachate rather than the vertical migration. The FLAC model results are in close agreement with the SUTRA model results of McCreanor [11] when the leachate injection is followed for continuous application for three weeks with respect to different application rates and saturated hydraulic conductivity.

To evaluate the effect of the intermittent leachate application in a VW on the moisture distribution and lateral width of the wetted area, the intermittent leachate application for $8 \mathrm{hr}$ on and $16 \mathrm{hr}$ off is simulated for leachate injection rates of 5,10 , and $20 \mathrm{~m}^{3} /$ day operated for three weeks and those results are plotted in Figure 19 for the different injection rates with a constant MSW saturated hydraulic conductivity of $10^{-3} \mathrm{~cm} / \mathrm{s}$. Unlike the results for the continuous leachate injection, in the case of the intermittent application of 


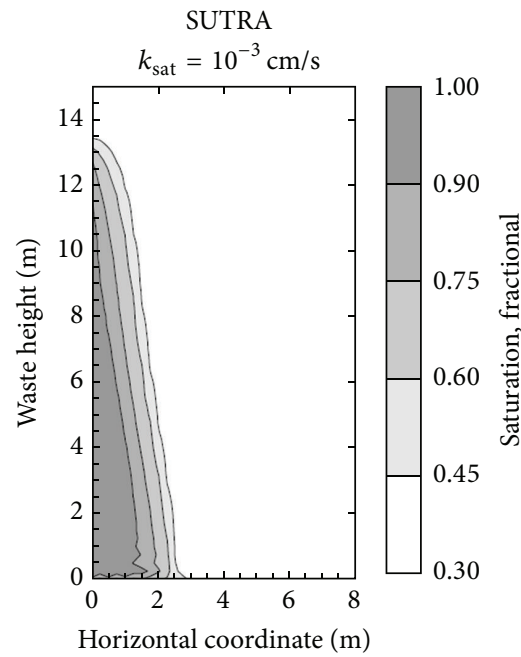

(a)

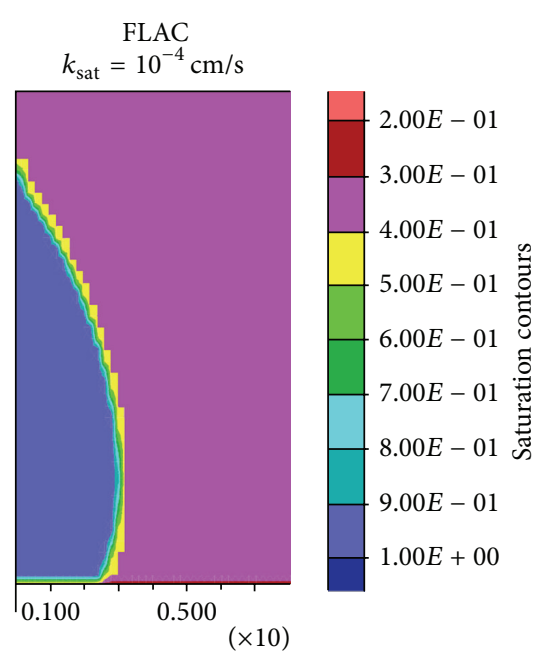

(d)

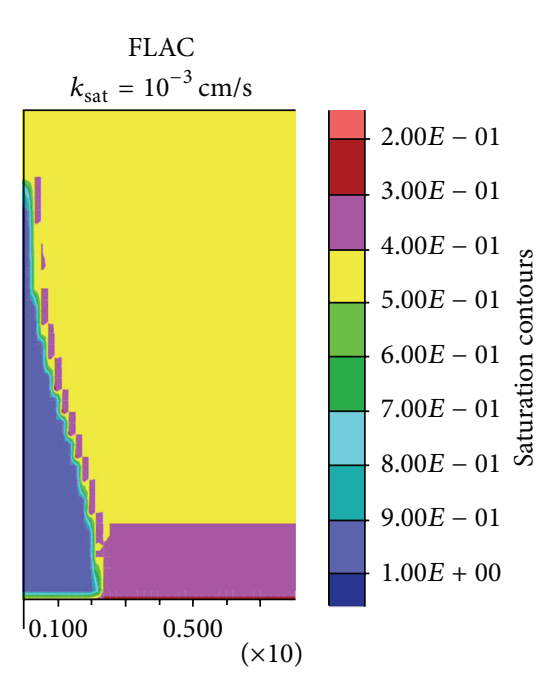

(b)

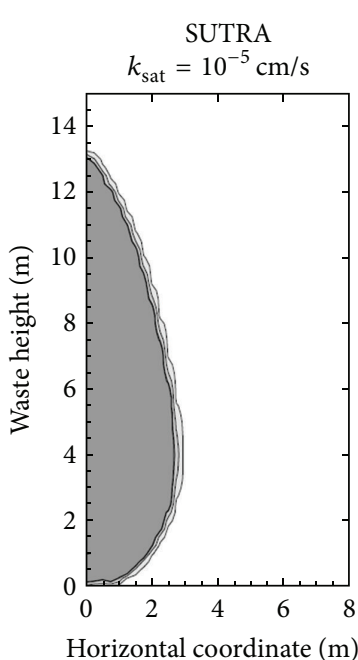

(e)

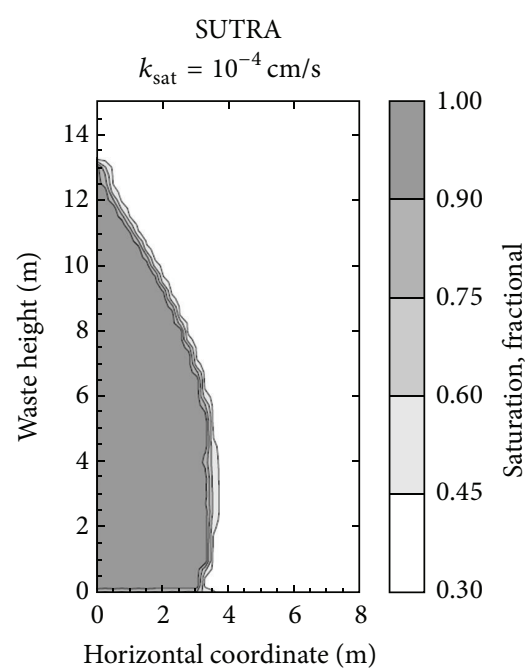

(c)

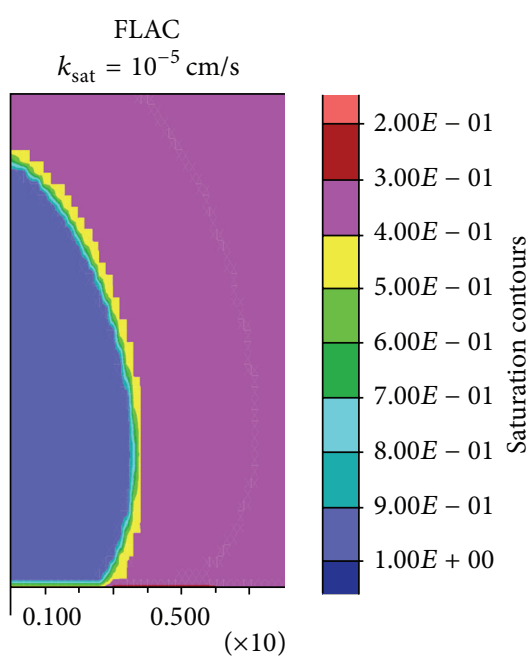

(f)

FIGURE 18: Saturation isoclines for VW operated continuously at rate of $10 \mathrm{~m}^{3} /$ day after three weeks flow.
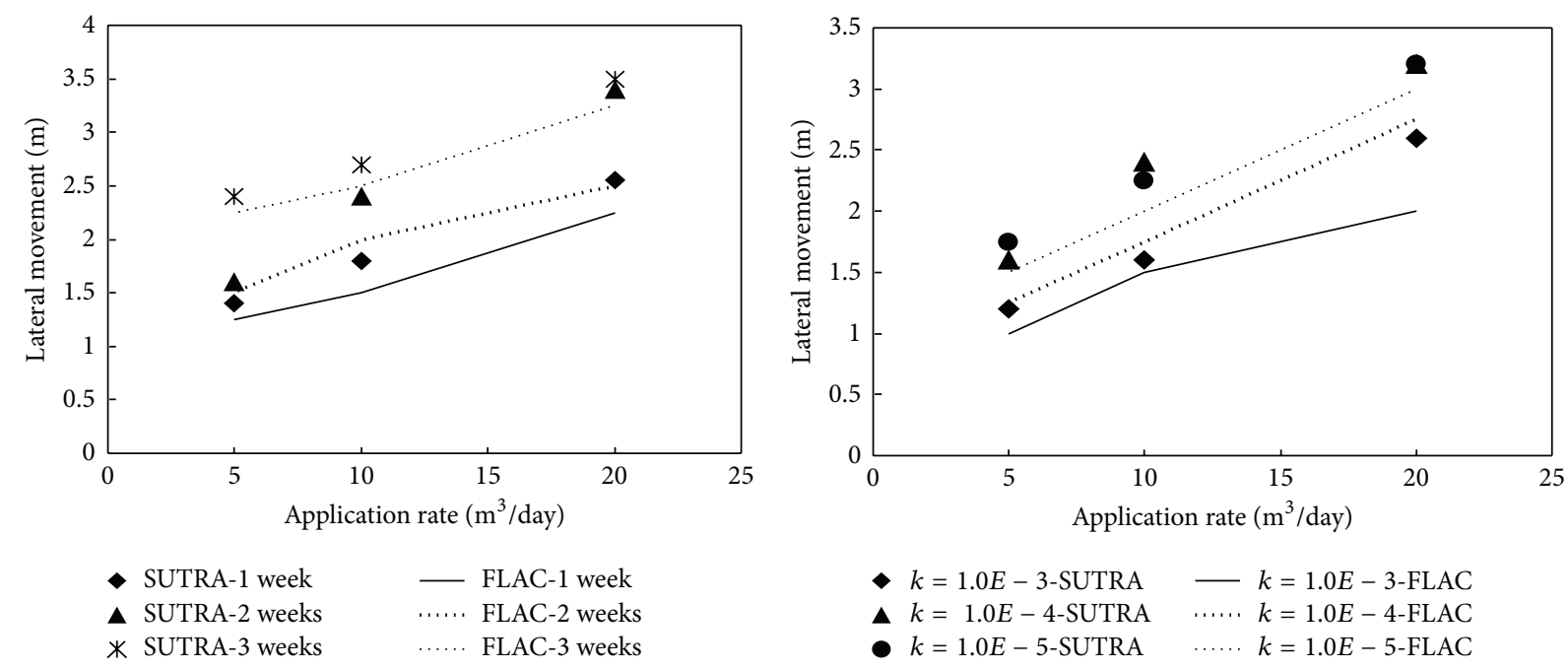

(b)

FIGURE 19: Lateral movement versus application rate with intermittent leachate injection for (a) four weeks and (b) saturated hydraulic conductivity for one week flow. 


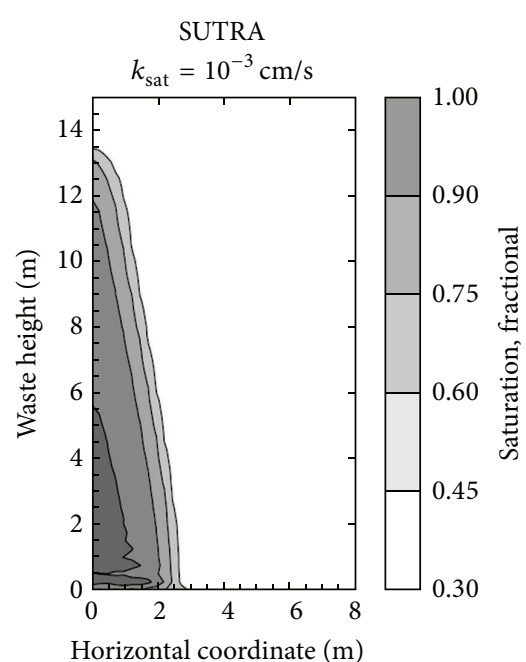

(a)

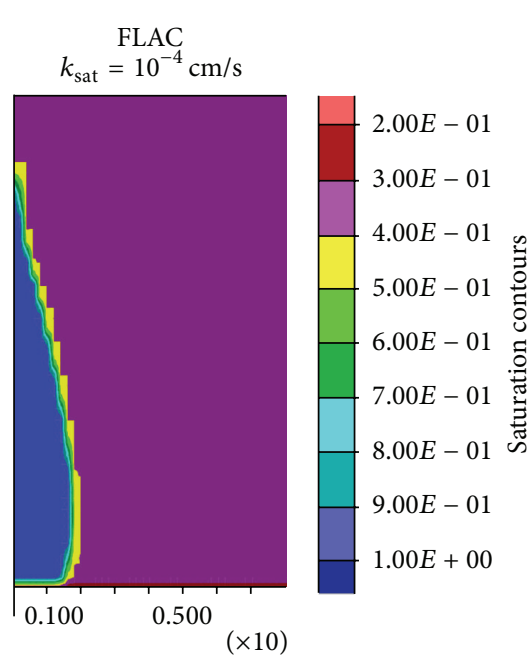

(d)

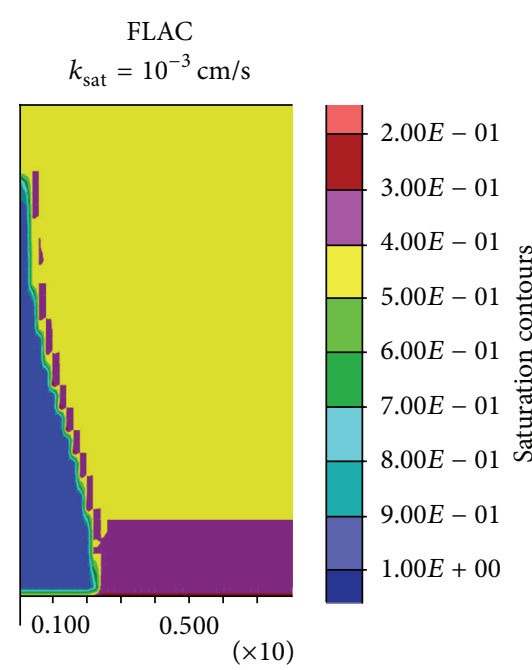

(b)

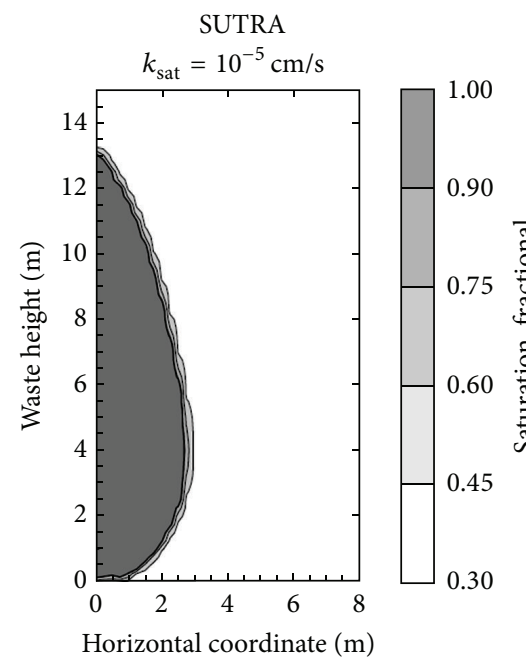

(e)

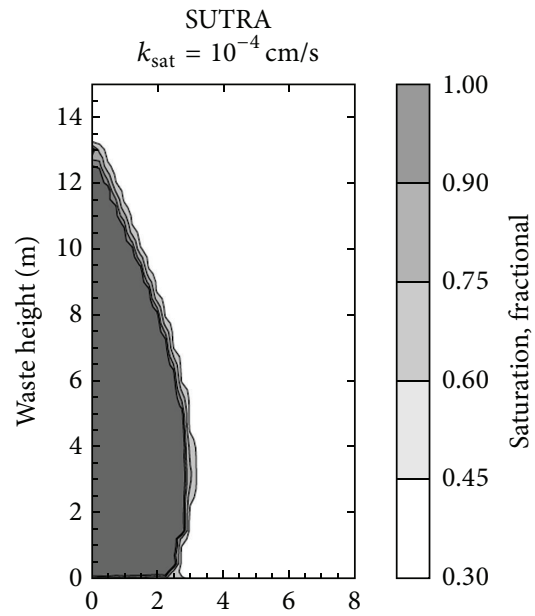

Horizontal coordinate $(\mathrm{m})$

(c)

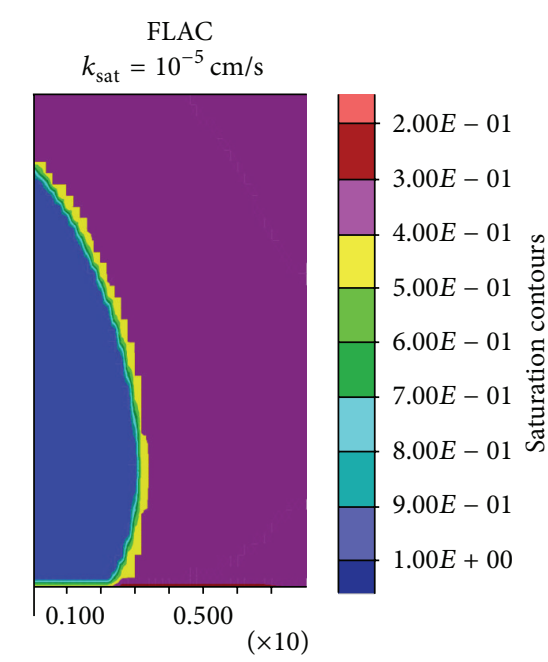

(f)

FIGURE 20: Saturation isoclines for VW operated intermittently at leachate application rate of $10 \mathrm{~m}^{3} /$ day after three weeks flow.

the leachate, the lateral width of the wetted area caused by the injection has to be less. This is demonstrated in the FLAC model results. However, this is where the results from the two models deviate. The SUTRA model presented values for the intermittent leachate injection that are either equal to or higher than those found in the continuous application. Since the leachate injection was stopped for 16 hours, the injected leachate tries to migrate in a vertical downward direction due to gravity, thus reducing the lateral width of the wetted area. However, the SUTRA model overestimated the effect of intermittent leachate application on lateral movement producing either the same or a higher lateral width when compared to continuous leachate injection. On the other hand, since the leachate injection stopped for a few hours as part of the intermittent application operation, the predicted lateral width from the FLAC simulation is less than that resulting from the continuous leachate application. For example, simulation results produced by FLAC after three weeks operation, lateral width for saturated hydraulic conductivity of $10^{-3} \mathrm{~cm} / \mathrm{s}$ was 3,25 , and $5.75 \mathrm{~m}$, respectively, for injection rates of 5,10 , and $20 \mathrm{~m}^{3} /$ day, and the same are $2.25,3$, and $5 \mathrm{~m}$, respectively, for injection rates of 5 , 10 , and $20 \mathrm{~m}^{3} /$ day when intermittent leachate application is followed. Moreover, the lateral width, saturation levels, and leachate migration depend greatly on the unsaturated hydraulic properties of the MSW.

Figure 20 illustrates the saturation isoclines comparing the effect of the mode of leachate application for MSW having saturated hydraulic conductivity of $10^{-3} \mathrm{~cm} / \mathrm{s}$ and injection rate of $10 \mathrm{~m}^{3} /$ day. The comparison of the saturation isoclines between the models indicates that the shape and the saturation levels are in close agreement. Therefore, the validation of the FLAC model when its results are compared to the results produced by McCreanor [11] using this SUTRA model increases the confidence in and dependability of the two-phase FLAC model used in this study as a means to 


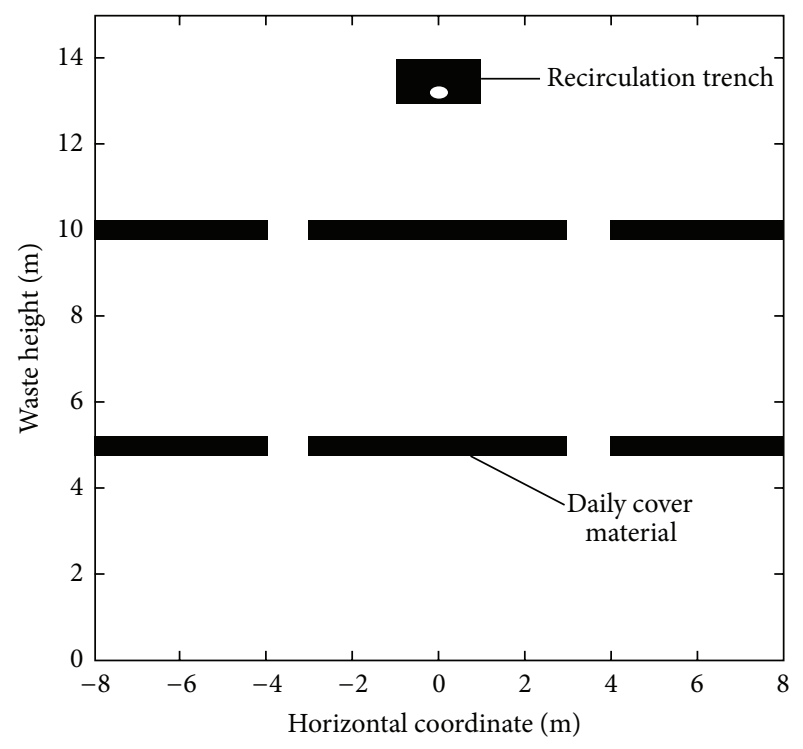

(a)

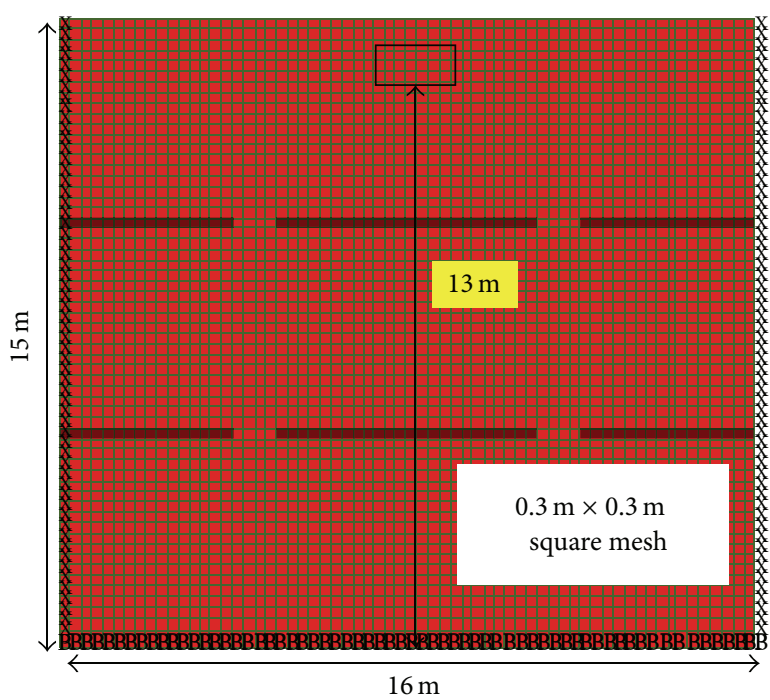

(b)

Figure 21: (a) Conceptual model for effect of daily cover layer implemented by McCreanor [11]; (b) model discretization in two-phase flow model.

effectively estimate the moisture distribution in a bioreactor landfill.

5.1.3. Effects of Daily Cover Modeling. Daily cover is the material deposited on top of the MSW to cover it after the MSW lifts are compacted at the end of the day's landfill operation. The daily cover material may be clay, sand, shredded tires, used carpets, foams, removable geotextiles, or traps [11]. Therefore, the location, thickness, and material, and hydraulic properties of the daily cover can greatly affect the moisture distribution in a bioreactor landfill. For these SUTRA-based simulations of the effects of the daily cover material, the saturated hydraulic conductivity of the material is given as $10^{-5} \mathrm{~cm} / \mathrm{s}$ to represent typical cover materials (i.e., clay, sand, or shredded tires) on the injected leachate migration in a landfill cell that uses a HT as its leachate recirculation system. The study assumed the saturated hydraulic conductivity of the MSW as $10^{-3} \mathrm{~cm} / \mathrm{s}$ and the leachate injection rates of 2,4 , and $8 \mathrm{~m}^{3} / \mathrm{d} / \mathrm{m}$ length of trench. In this conceptual model, the HT is $2 \mathrm{~m}$ wide by $1 \mathrm{~m}$ deep and is located $13 \mathrm{~m}$ above the leachate collection system. The daily cover material was placed at two levels located $5 \mathrm{~m}$ and $10 \mathrm{~m}$ above the LCS, with a breached configuration of $1 \mathrm{~m}$ between the levels (Figure 21(a)). In this simulation of the fluid flow in the landfill cell, both the MSW and daily cover were considered to be homogeneous and isotropic. The moisture distribution was studied for the condition where the saturated hydraulic conductivity was $10^{-5} \mathrm{~cm} / \mathrm{s}$ for daily cover material and MSW $10^{-3} \mathrm{~cm} / \mathrm{s}$ for three leachate injection rates of 2,4 , and $8 \mathrm{~m}^{3} / \mathrm{d} / \mathrm{m}$ length of trench. The leachate injection was performed intermittently following the pattern of $8 \mathrm{hr}$ on and $16 \mathrm{hr}$ off over one week. Based on the simulation results, the investigator concluded that if a daily cover is used, the best material would be a degradable material, such as wood chips, and expressed the importance of using the breached configuration of daily cover material to avoid any lateral migration of injected leachate that could cause slope stability issues. In landfill practice, daily covers are usually placed on MSW deposits on daily basis to limit odors, vectors, fires, scavenging, and so forth. These daily cover materials should have high enough permeability to adequately distribute moisture in underlying MSW materials and avoid any perched leachate conditions. Otherwise, it can result in excess generation of pore water and pore gas pressure within an isolated zone and adversely impact the overall stability of landfill. However, to the authors' knowledge, the long-term degradation effects of daily covers are generally not considered, since these materials are provided only for a very short duration and any long-term impacts are negligible.

The two-phase flow FLAC model consists of a bioreactor cell that is $16 \mathrm{~m}$ wide and $15 \mathrm{~m}$ high (Figure 21(b)). In this case, the daily cover material is placed at two locations, $5 \mathrm{~m}$ and $10 \mathrm{~m}$ above the LCS with breached configuration with a $1 \mathrm{~m}$ breach between the levels. The middle portion of the cover material is extended $6 \mathrm{~m}$ laterally (wide) and the side layers connecting edges extend for $4 \mathrm{~m}$ from the boundary of the cell. Based on the grid size analysis, the model is discretized by $0.3 \mathrm{~m}$ square grids. All the boundaries are considered impermeable, and the pore water pressure at the bottom of the landfill is fixed to zero to simulate the leachate collection system. The $2 \mathrm{~m}$ wide by $1 \mathrm{~m}$ deep HT used as the leachate recirculation system is located $13 \mathrm{~m}$ above the LCS, in the middle of the landfill cell. It is backfilled with highly permeable material that has a saturated hydraulic conductivity of $10^{-2} \mathrm{~cm} / \mathrm{s}$ and initial porosity of $30 \%$. The initial model parameters are those appearing in the published literature and these values are listed in Table 1. Simulations 
are performed for the different MSW saturated hydraulic conductivities $10^{-3}, 10^{-4}$, and $10^{-5} \mathrm{~cm} / \mathrm{s}$ and leachate injection rates of 2,4 , and $8 \mathrm{~m}^{3} /$ day/m length of trench.

Following McCreanor [11], both the MSW and daily cover material are considered homogeneous and isotropic. The simulation results obtained from the FLAC and SUTRA models for saturation isoclines are compared in order to contrast the shape and saturation levels found in the landfill. Figure 22 shows the comparison of results for scenarios 1 through 3. It is clear from the plots contrasting the shape of isoclines at the different injection rates that the SUTRA and FLAC simulations produce very similar results. This increases the confidence in the dependability of the results. However, the saturation levels differ slightly. This variation is expected since the two-phase flow FLAC model considers the unsaturated flow of wetting and nonwetting fluids and the unsaturated hydraulic properties assumed in FLAC model are representative values for the MSW only. If the unsaturated hydraulic properties for the MSW from the Florida landfill were known, the two-phase flow model would likely provide results that are closer to those generated in SUTRA by McCreanor [11].

The saturation levels simulated by FLAC model possess minor differences from those in McCreanor [11]. The explanation is that the saturation level reached during the intermittent leachate recirculation is greatly affected by the unsaturated hydraulic properties of the MSW. Therefore, modeling must include the selection of the proper hydraulic or unsaturated hydraulic properties of the MSW and specific to type of MSW, as well as the age, overburden pressure, composition, and other factors.

\subsection{Haydar and Khire [12], [13] and Khire and Mukherjee [14] Studies}

5.2.1. Horizontal Trench System Study. Haydar and Khire [12] report on a mathematical modeling study in which they used HYDRUS-2D to simulate the leachate injection in MSW where the landfill was modeled to be $100 \mathrm{~m}$ wide and $20 \mathrm{~m}$ high. The hydraulic properties of silt loam were assumed as representative of the MSW (Table 6). The MSW was also assumed to be homogeneous and isotropic with the saturated hydraulic conductivity of $1 \times 10^{-4} \mathrm{~cm} / \mathrm{s}$. The FLAC model was used to simulate these conditions. Here, the leachate was continuously injected into a HT located $13 \mathrm{~m}$ above the leachate collection and removal system (LCRS) until the steady state condition was attained. The results of the simulation for the saturation isoclines and maximum wetted width of MSW are compared with those from the HYDRUS model.

The FLAC simulation adopted the same bioreactor landfill model for its model validation (Figure 23), as shown elsewhere [12], as well as the same HT placement, boundary, and initial conditions. The HT was assumed to be filled with the highly permeable gravel material. Based on the grid size analysis, the model is discretized into $0.3 \mathrm{~m}$ square grids. Since the objective of this study is an examination of the flow only problem, any deformation in the system is fixed to zero (lateral and vertical deformation at bottom of landfill cell, and lateral deformation on the sides of the landfill cell). The hydraulic boundary conditions were assumed to be impermeable, and the pore water pressure at the bottom of the landfill is fixed to zero to simulate the leachate collection system and replicate the condition seen by Haydar and Khire [12] where the leachate does not accumulate above the LCS. The initial model parameters are selected from published literature and the values are listed in Table 6. Simulations were performed with saturated hydraulic conductivity of MSW as $10^{-4} \mathrm{~cm} / \mathrm{s}$, and leachate injection rate of $4 \mathrm{~m}^{3} /$ day $/ \mathrm{m}$ length of trench.

The simulation was conducted until the steady state condition was attained. Figure 24 shows comparison of the wetted widths predicted by HYDRUS-2D and FLAC. The wetted width simulated in HYDRUS-2D was $25 \mathrm{~m}$ for MSW having saturation of more than $45 \%$ and the same simulated in FLAC is $24.5 \mathrm{~m}$; a close agreement of the results of Haydar and Khire [12]. Thus, the two-phase flow FLAC model can reasonably predict the moisture distribution predicted by HYDRUS 2D.

5.2.2. Vertical Well and Drainage Blanket Systems Studies. Khire and Mukherjee [14] and Haydar and Khire [13] reported modeling of vertical well and drainage blanket recirculation systems, respectively, following the similar procedure as that for horizontal trenches. FLAC modeling of these cases was also performed, and a reasonable good agreement between the FLAC and HYDRUS 2D modeling results was found [15].

\section{Summary and Conclusion}

The FLAC numerical two-phase flow model was validated based on both laboratory and field studies as well as previous single-phase flow modeling studies. These validation studies demonstrate that the results produced by the FLAC model had an average error of less than $10 \%$ in the moisture distribution values with regard to the saturation levels, wetted MSW width, and wetted MSW area.

It is critical to predict field studies accurately in order for the model to be useful for practice. It is demonstrated that the selection of appropriate material properties, and boundary and initial conditions is critical for the two-phase flow FLAC model. On comparison, the model results were closely matched with the field results, demonstrating the potential for using the two-phase flow FLAC model for fieldscale studies.

The FLAC model was also validated against the published laboratory studies, with their controlled conditions. By modeling similar laboratory situations using the numerical tool, this study again produced results that are close. The simulation results demonstrated that the FLAC model is in agreement with the published laboratory studies and an efficient means of producing similar results.

A few studies presented both data collected in the field and simulations. These studies were also replicated using the FLAC two-phase flow model, to verify the results and 


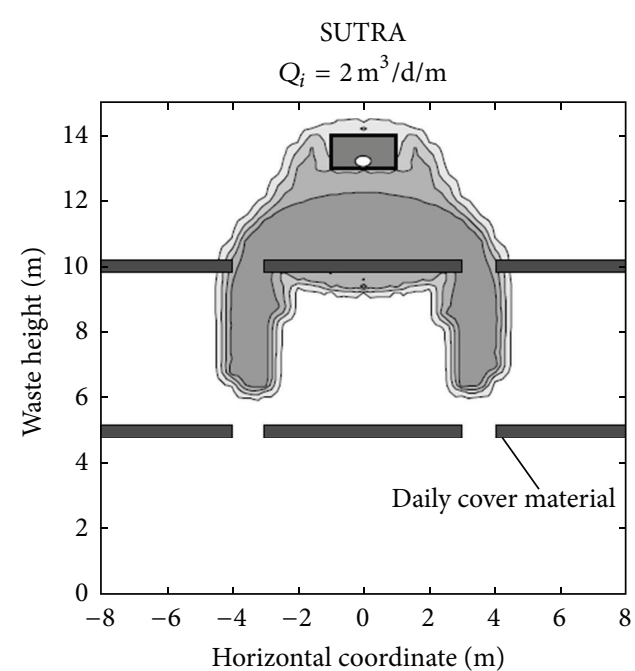

(a)

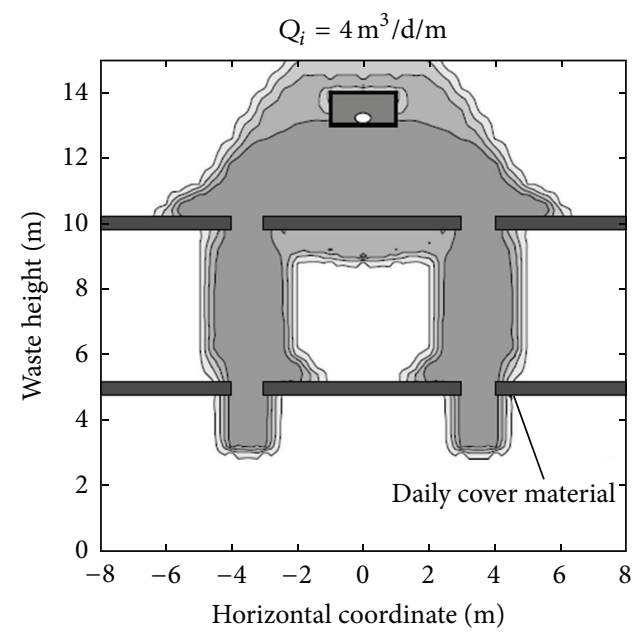

(c)

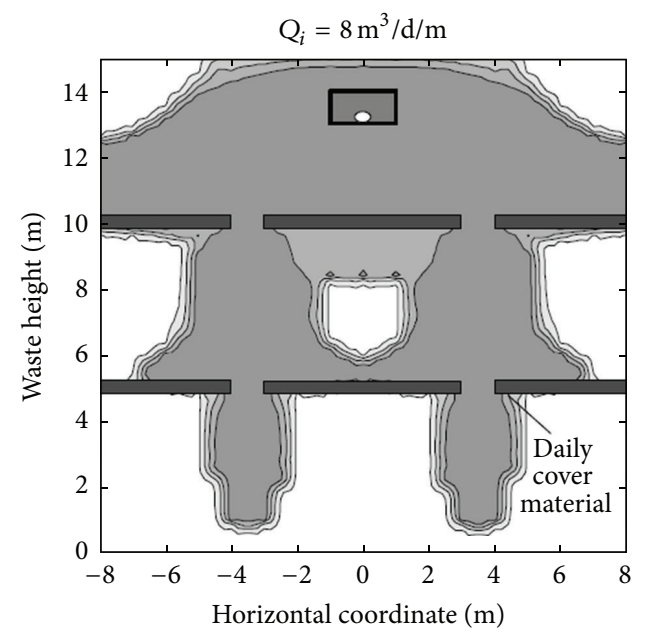

(e)
FLAC
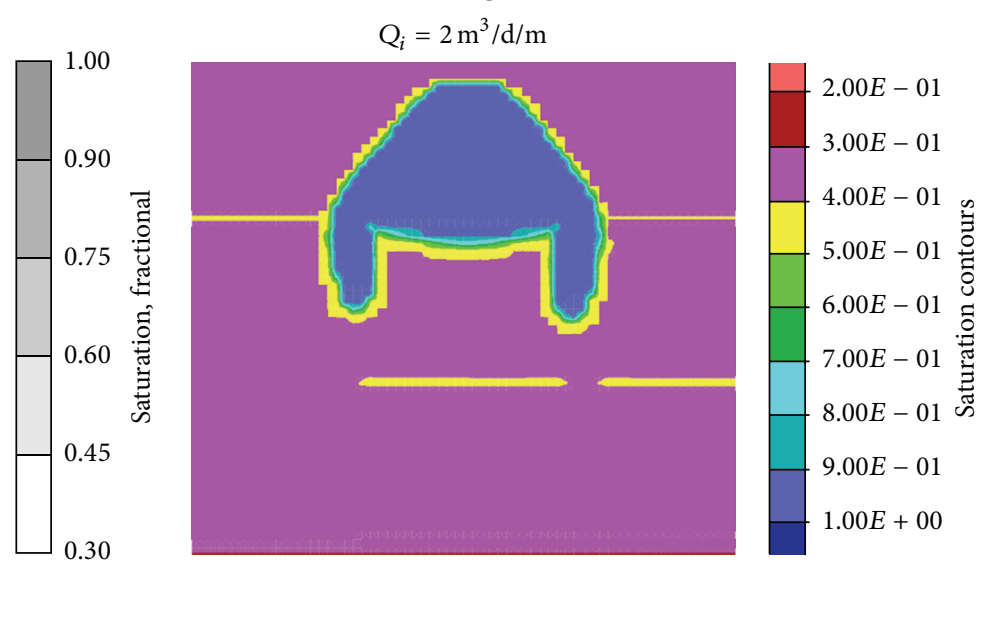

(b)
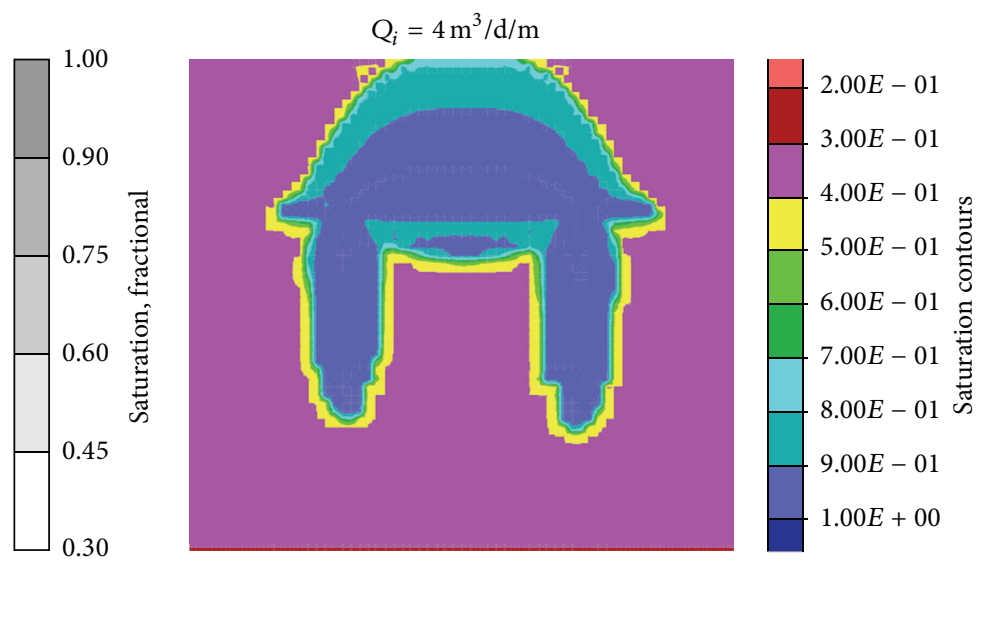

(d)
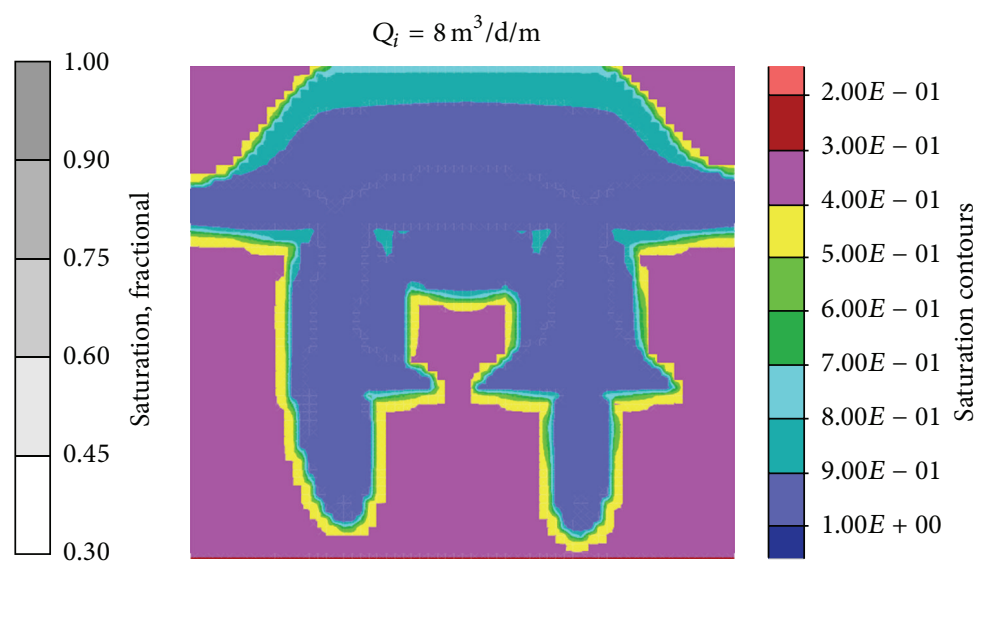

(f)

FIGURE 22: Leachate routing in a landfill with daily cover layer permeability $=10^{-5} \mathrm{~cm} / \mathrm{s}$; MSW permeability $=10^{-3} \mathrm{~cm} / \mathrm{s}$, at different leachate injection rates operated intermittently ( $8 \mathrm{hr}$ on $16 \mathrm{hr}$ off) operated for one week. 
TABLE 6: Initial conditions used for model validation as per Haydar and Khire [12].

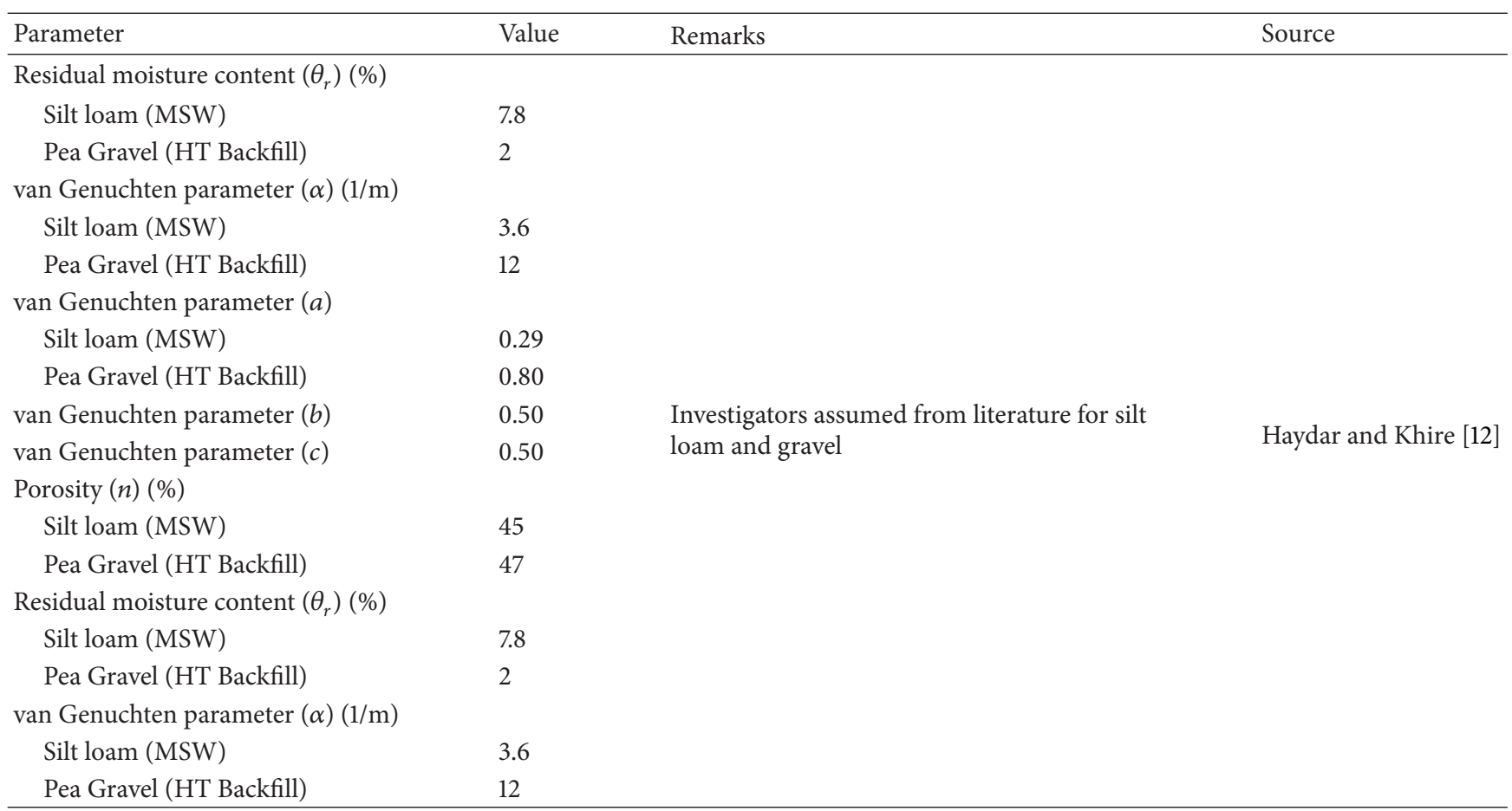

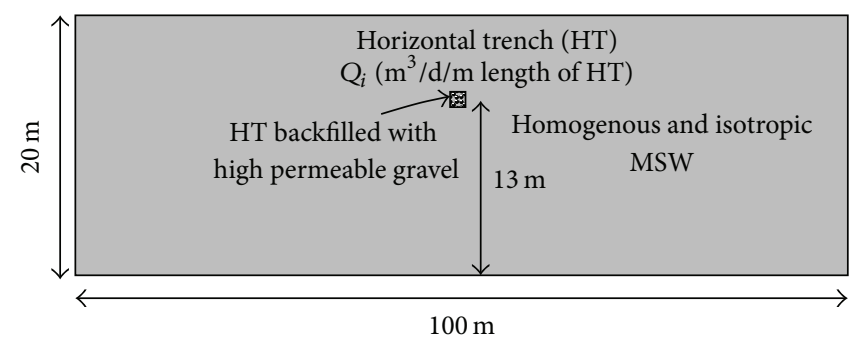

FIGURE 23: Landfill model developed for model validation in two-phase flow numerical model with Haydar and Khire [12] studies.

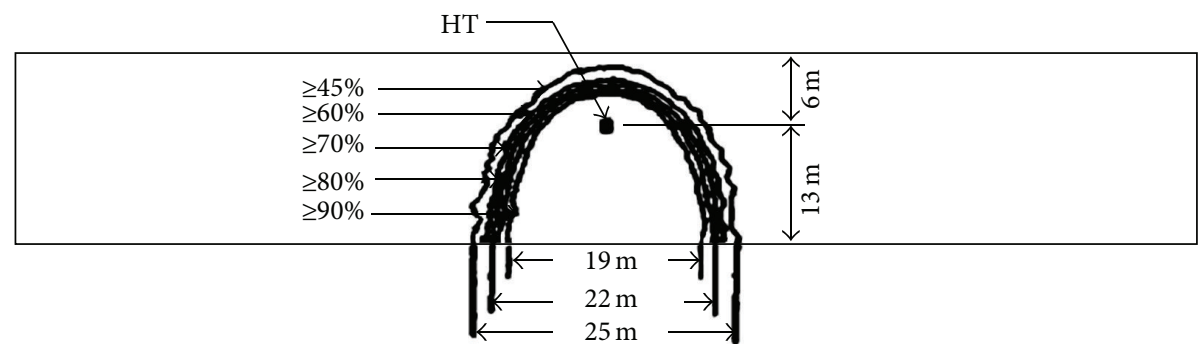

(a)

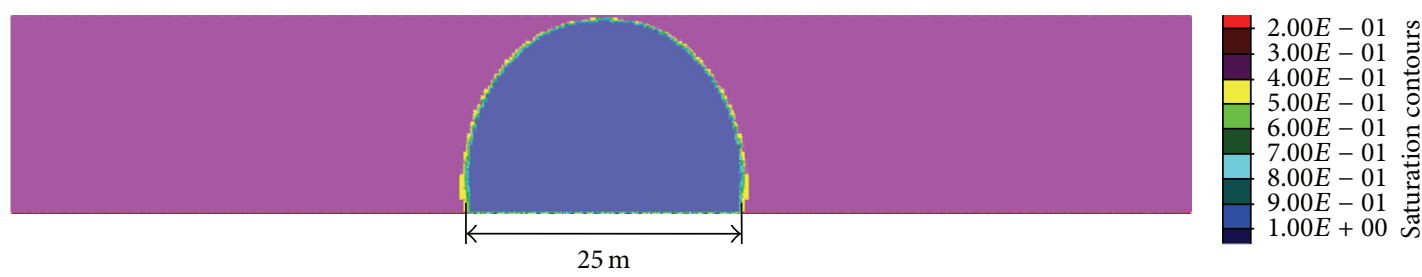

(b)

FIGURE 24: Simulated wetted width and saturation contours at steady state for a single HT by (a) Haydar and Khire [12]; (b) FLAC results. 
validate this model. Interestingly, the errors presented in the previous published studies were addressed very well by twophase flow model. In fact, the results provided data that was actually missing from the original studies, which further proves its effectiveness as a modeling tool when analyzing flow in unsaturated MSW.

As with the case of any numerical modeling program, the two-phase flow model presented in study also has few limitations. The study mainly focused on fluid flow in bioreactor landfill considering the effects of several key parameters such as MSW heterogeneity and saturated and unsaturated hydraulic properties on landfill performance during the operations of leachate injections. The effects of coupled flowmechanical behavior are neglected. Moreover, the effects of biodegradation are also not considered in this study. Current research by the authors is aimed at developing coupled flowmechanical-biodegradation modeling of bioreactor landfills to predict the long-term performance of bioreactor landfills.

Overall, the two-phase flow FLAC model represents the unsaturated MSW in a way that is equal to or better than the published studies; and therefore, it can be implemented to analyze the flow in a bioreactor landfill. The model will prove to be an effective tool capable of providing information necessary for the design of effective leachate recirculation systems in bioreactor landfills to achieve uniform moisture distribution across the entire landfill.

\section{Conflict of Interests}

The authors declare that there is no conflict of interests regarding the publication of this paper.

\section{Acknowledgment}

This project was funded by the U.S. National Science Foundation (Grant CMMI no. 0600441), which is gratefully acknowledged.

\section{References}

[1] ITRC (Interstate Technology and Regulatory Council), Characterization, Design, Construction, and Monitoring of Bioreactor Landfills, Alternative Landfill Technologies Team, Washington, DC, USA, 2006.

[2] ICGI (ITASCA Consulting Group), Fast Lagrangian Analysis of Continua (FLAC) Version 7.0: Fluids-Mechanical Interaction, User's Manual, Minneapolis, Minn, USA, 4th edition, 2011.

[3] K. R. Reddy, H. S. Kulkarni, and M. V. Khire, "Two-phase modeling of leachate recirculation using vertical wells in bioreactor landfills," Journal of Hazardous, Toxic, and Radioactive Waste, vol. 17, no. 4, pp. 272-284, 2013.

[4] J. Capelo and M. A. H. de Castro, "Measuring transient water flow in unsaturated municipal solid waste-a new experimental approach," Waste Management, vol. 27, no. 6, pp. 811-819, 2007.

[5] G. Stoltz, A. Tinet, M. J. Staub, L. Oxarango, and J. Gourc, "Moisture retention properties of municipal solid waste in relation to compression," Journal of Geotechnical and Geoenvironmental Engineering, vol. 138, no. 4, pp. 535-543, 2012.
[6] K. R. Reddy, J. Gangathulasi, N. S. Parakalla, H. Hettiarachchi, J. E. Bogner, and T. Lagier, "Compressibility and shear strength of municipal solid waste under short-term leachate recirculation operations," Waste Management and Research, vol. 27, no. 6, pp. 578-587, 2009.

[7] M. J. Staub, J. P. Gourc, J. P. Laurent et al., "Long-term moisture measurements in large-scale bioreactor cells using TDR and neutron probes," Journal of Hazardous Materials, vol. 180, no. 1, pp. 165-172, 2010.

[8] M. M. Haydar and M. V. Khire, "Field-scale testing of leachate recirculation blanket made up of scrap tires at a MSW landfill," in Proceedings of the 19th International Conference on Solid Waste Technology and Management, Philadelphia, Pa, USA, 2004.

[9] R. Kadambala, T. G. Townsend, P. Jain, and K. Singh, “Temporal and spatial pore water pressure distribution surrounding a vertical landfill leachate recirculation well," International Journal of Environmental Research and Public Health, vol. 8, no. 5, pp. 1692-1706, 2011.

[10] K. R. Reddy, H. Hettiarachchi, N. Parakalla, J. Gangathulasi, J. Bogner, and T. Lagier, "Hydraulic conductivity of MSW in landfills," Journal of Environmental Engineering, vol. 135, no. 8, pp. 1-7, 2009.

[11] P. T. McCreanor, Landfill leachate recirculation systems: mathematical modeling and validation [Ph.D. thesis], Department of Civil and Environmental Engineering, , University of Central Florida, Orlando, Fla, USA, 1998.

[12] M. M. Haydar and M. V. Khire, "Leachate recirculation using horizontal trenches in bioreactor landfills," Journal of Geotechnical and Geoenvironmental Engineering, vol. 131, no. 7, pp. 837847, 2005.

[13] M. M. Haydar and M. V. Khire, "Leachate recirculation using permeable blankets in engineered landfills," Journal of Geotechnical and Geoenvironmental Engineering, vol. 133, no. 4, pp. 360371, 2007.

[14] M. V. Khire and M. Mukherjee, "Leachate injection using vertical wells in bioreactor landfills," Waste Management, vol. 27, no. 9, pp. 1233-1247, 2007.

[15] H. S. Kulkarni, Optimization of leachate recirculation systems in bioreactor landfills [Ph.D. thesis], University of Illinois, Chicago, Ill, USA, 2012.

[16] A. P. Hudson, J. K. White, R. P. Beaven, and W. Powrie, "Modelling the compression behaviour of landfilled domestic waste," Waste Management, vol. 29, no. 3, pp. 259-269, 2004.

[17] F. Olivier and J. P. Gourc, "Hydro-physico-mechanics of a mechanically pretreated waste in a large scale laboratory cell," in Proceedings of the International Workshop on HydroPhysicoMechanics of Landfills, vol. 4, pp. 1-4, Grenoble, France, 2005. 

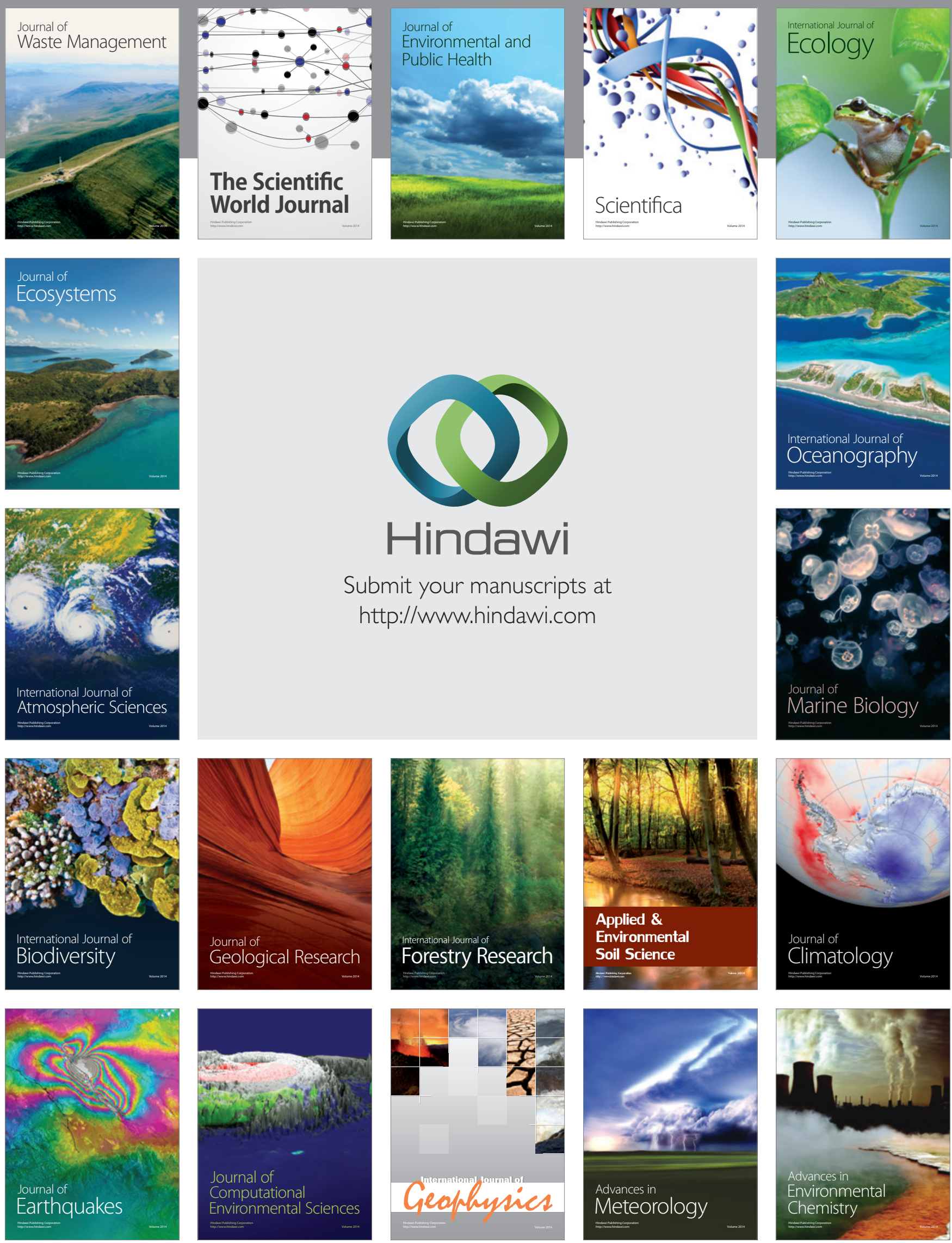